\title{
Connecting primitive phase separation to biotechnology, synthetic biology, and engineering
}

\author{
Tony Z JiA ${ }^{1,2 *}$, $\begin{gathered}\text { Po-Hsiang Wang } \\ \text { Irena Mamajanov }\end{gathered}$ \\ ${ }^{1}$ Earth-Life Science Institute, Tokyo Institute of Technology, 2-12-1-IE-1 Ookayama, Meguro-ku, \\ Tokyo 152-8550, Japan \\ ${ }^{2}$ Blue Marble Space Institute of Science, 1001 4th Ave., Suite 3201, Seattle, Washington 98154, USA \\ ${ }^{3}$ Graduate Institute of Environmental Engineering, National Central University, Zhongli Dist, 300 \\ Zhongda Rd, Taoyuan City 32001, Taiwan \\ ${ }^{4}$ Cell Biology Center, Institute of Innovative Research, Tokyo Institute of Technology, Nagatsuta-cho \\ 4259, Midori-ku, Yokohama 226-8503, Japan \\ *Corresponding author (Email, tzjia@elsi.jp)
}

MS received 8 April 2021; accepted 20 July 2021

\begin{abstract}
One aspect of the study of the origins of life focuses on how primitive chemistries assembled into the first cells on Earth and how these primitive cells evolved into modern cells. Membraneless droplets generated from liquid-liquid phase separation (LLPS) are one potential primitive cell-like compartment; current research in origins of life includes study of the structure, function, and evolution of such systems. However, the goal of primitive LLPS research is not simply curiosity or striving to understand one of life's biggest unanswered questions, but also the possibility to discover functions or structures useful for application in the modern day. Many applicational fields, including biotechnology, synthetic biology, and engineering, utilize similar phaseseparated structures to accomplish specific functions afforded by LLPS. Here, we briefly review LLPS applied to primitive compartment research and then present some examples of LLPS applied to biomolecule purification, drug delivery, artificial cell construction, waste and pollution management, and flavor encapsulation. Due to a significant focus on similar functions and structures, there appears to be much for origins of life researchers to learn from those working on LLPS in applicational fields, and vice versa, and we hope that such researchers can start meaningful cross-disciplinary collaborations in the future.
\end{abstract}

Keywords. Biomaterials; biomedicine; biotechnology; engineering; interdisciplinary; origins of life; phase separation; protocell

\section{Introduction}

One of the goals of origins of life $(\mathrm{OoL})$ research is to understand how the first cells on Earth, i.e., protocells, formed. While it is unclear what these protocells were exactly composed of, the OoL field has studied many model systems that mimic compartments potentially present on early Earth. These model systems include fatty acid and phospholipid bilayer membrane vesicles (Chen and Walde 2010; Imai and Walde 2019), oil-in- water droplets (Hanczyc 2014; Zwicker et al. 2016), mineral pores (Westall et al. 2018), and membraneless droplet systems (Fox 1976; Poudyal et al. 2018), among others (Monnard and Walde 2015). In particular, membraneless droplet systems formed from phase separation have been explored as potential protocell models since the early 1900s, when Oparin and Haldane jointly proposed the existence of so-called membraneless coacervate droplets (Lanham 1952; Tirard 2017). 
Although initially proposed as primitive compartments, liquid-liquid phase separation (LLPS) has been studied abundantly in biology as well (Yoshizawa et al. 2020). For example, it is believed that phase separation and membraneless organelles control many essential cellular processes including gene regulation (Peng et al. 2020), cell division (Ong and Torres 2020; Peng et al. 2020), tumorigenesis (Nozawa et al. 2020; Jiang et al. 2020), and development of diseases such as amyotrophic lateral sclerosis (Lin et al. 2016), among others (Yoshizawa et al. 2018; Boeynaems et al. 2018). However, while the number of recent studies reporting LLPS-controlled cellular processes have increased significantly compared to just a few years prior, there is still some skepticism in the field regarding the exact mechanisms of the contributions that phase separation has on cellular processes (McSwiggen et al. 2019), and specific methods or techniques suitable for analysis of biological LLPS have yet to be agreed upon amongst researchers in the field (Kamimura and Kanai 2021). As such, more rigorous and wide-spanning research into biological phase separation processes must continue, among the renewed interest (and the warranted skepticism).

Skepticism is not a unique concept within biological LLPS research, and is prevalent in OoL research as well, where a wide range of theories are pursued by a number of researchers from many fields of study (Lazcano and Miller 1996; Peretó 2005; White 2007; Phillips 2010; Bruylants et al. 2011; Cleaves 2012, 2013; Scharf et al. 2015; Knab 2016; Krishnamurthy 2018; Benner et al. 2019; Butch et al. 2021). In particular, it is not clear how membraneless droplets could have assembled on early Earth, let alone accomplished functions that a primitive cell would have performed, although many theories exist. Nevertheless, this should not preclude researchers from exploring important and difficult OoL-related questions, especially regarding the role of LLPS at the origins of life (in particular, these questions are worth studying because of their difficulty!). In fact, a number of LLPS systems have been discovered and characterized in the context of primitive compartments, including aqueous two-phase systems (ATPS) (Keating 2012); coacervates composed of a combination of nucleotides, nucleic acids, peptides, and other polymers (Koga et al. 2011; Ghosh et al. 2020; Abbas et al. 2021); and membraneless microdroplets generated from polyesters and other primitive 'nonbiological' polymers (Jia et al. 2019, 2021a; Chandru et al. 2020a, b), among others.
In these prebiotic simulation studies, phase-separated compartments are assembled in vitro in the laboratory by utilizing biomolecules that may have been present on early Earth. The prebiotic milieu was likely very 'messy', and many laboratory simulations focus on utilizing a small, isolated portion of the prebiotic milieu for tractability purposes. The experiments used to study primitive phase separation can be similar to the approaches taken by applicational fields such as biotechnology and synthetic biology, albeit with somewhat different goals and starting materials. Primitive LLPS research often focuses on the merits and demerits of various LLPS functions in the context of the emergence of life. These functions include enhancement of internal reaction rates (Poudyal et al. 2019a, b), segregation and concentration of analytes (Frankel et al. 2016), catalysis of chemical reactions (Pir Cakmak and Keating 2017), engulfment of other droplets (Qiao et al. 2017), and even growth and division upon application of external stimuli (Yin et al. 2016), among others.

While some in engineering fields may argue that the exhibited functions of primitive LLPS systems are quite simple compared to what can be achieved through synthetic biology (Meng and Ellis 2020), some modern applied processes use structures and/or functions observed in primitive LLPS. For example, drug delivery (Mohamed and Van der Walle 2008; Johnson and Wang 2014) and biomolecule purification (Xu et al. 2011) in biotechnology, synthetic microbioreactors (Garenne et al. 2016) and membraneless cellular organelle mimics (Yewdall et al. 2020; Deng 2020) in synthetic biology, pollution control systems in environmental engineering (Zhang et al. 2019), and flavor encapsulation in the food industry (Yeo et al. 2005; Madene et al. 2006) have used LLPS to accomplish functions. Recent OoL research has also been heavily focused on increasing the structural complexity of primitive LLPS, such as lipid layer- (Tang et al. 2014) and lipid vesicle-encapsulated (Pir Cakmak et al. 2019) coacervates, co-assembly of DNA liquid crystals in coacervates (Jia and Fraccia 2020; Fraccia and Jia 2020), mineral particle pickering emulsions scaffolded by polyethylene glycol (PEG)/dextran ATPS (Pir Cakmak and Keating 2017), and multiphase membraneless droplets (Lu and Spruijt 2020). Increases in structural complexity could lead to more complex emergent functions of LLPS, some of which may approach functions which could be used in modern engineering and biotechnology applications. Here, we briefly review the history of the study of LLPS in OoL research, followed by examples of LLPS used in 
biotechnology, synthetic biology, and engineering applications. Information gleaned from LLPS in OoL research and from applicational fields can be mutually beneficial to each other, and collaborations resulting in significant contributions both to new knowledge and novel technologies can result from such connections. Thus, we hope to promote further connections and discourse between OoL researchers and those in related fields such as biology, biochemistry, materials science, environmental engineering, and many others.

\section{LLPS systems as primitive compartments}

The assembly behavior of LLPS systems can be generally described using Flory-Huggins theory, which describes the thermodynamics of mixing polymer solutions (Flory 1942, 1945; Huggins 1942). Polymers in particular exhibit physical characteristics that cannot be predicted when compared to other ideal molecules of similar size, as different parts of a long polymer chain may act independently of other parts (Flory 1942). In particular, Flory-Huggins theory places all molecules and liquids within a mixture in a lattice, from which thermodynamic parameters such as entropy, enthalpy, and Gibbs free energy of mixing can be predicted; the Gibbs free energy of mixing is dependent on the average degree of polymerization (Wang et al. 2019). These parameters can then help to predict phase separation characteristics, including phase diagrams, of mixed polymer solutions (Tian et al. 2013; Lopes et al. 2020). Describing the thermodynamics of complex coacervation, a specialized case of LLPS resulting from binding of oppositely charged polymers, requires a modification of FloryHuggins theory (Veis 2011). Voorn and Overbeek modified the Flory-Huggins theory to take into account that phase separation of a complex coacervate does not result in complete depletion of either polymer in any phase (both polymers are present in both resulting phases, although perhaps at very low concentrations) (Overbeek and Voorn 1957). However, further detailed discussion of the physics of phase separation is beyond the scope of this review.

Since the initial proposals by Oparin and Haldane in the 1920s, several LLPS systems have been studied in an OoL context, even being proposed as model protocells. Here, we first introduce the concept of compartmentalization, describe the history of research regarding primitive compartments, and then present a broad overview of relevant primitive compartment systems, in particular focusing on those generated from phase separation.

\subsection{Compartmentalization}

The process by which any given volume of space is completely confined (internal space) and separated from the rest of the environment is considered compartmentalization. Household objects such as containers or vehicles such as cars or trains could be considered compartments that separate different objects. The compartment boundary itself is usually an interface, and it must be compatible and interact with both the internal and external components in some way. One such example of a compartment interface is a micellar boundary, which can be generated when washing oil from one's hands with soap; the amphiphilic soap molecules coat and encapsulate the oil molecules. The inner boundary of the soap micelle interacts with oil molecules, while the external boundary of the soap interacts with water molecules (Sorrenti et al. 2013). Such boundaries may also have variable porosity. Some are fairly porous, such as cheese wrapped in cheesecloth, allowing some internal and external components to exchange. Other compartment boundaries are relatively non-porous, such as a water balloon, which allows very little internal/external component exchange. Compartments can also be of many sizes, from nanomachines on the nanoscale (Endo and Sugiyama 2018) all the way to planets, which may contain a variety of geological and chemical processes (Vita-Finzi and Fortes 2013).

Perhaps one of the most important functions of compartments is for the internal components inside a compartment to have different properties (physical, chemical, etc.) than the excluded components, although this is not guaranteed. One example is an in-flight airplane, which controls temperature, pressure, and oxygen content of the air within the fuselage to allow humans to survive. Outside of a flying airplane, the air is too cold and oxygen-poor to sustain human life, although some extremophiles have been found in the upper stratosphere (Smith et al. 2018). However, when the airplane boundary is made more porous (for example, through opening a door), equilibration results in the internal components being largely equivalent to those of the excluded components. Exclusion through compartment boundaries can also be explored in biology at various scales. At the sub-cellular scale, the internal chemical environment within each organelle is 
distinctly different from the cellular cytoplasm and other organelles. Thus, different organelles can perform essential cellular functions such as nutrient synthesis (Fagone and Jackowski 2009), waste export (Ito et al. 2014), and gene expression regulation (Drino and Schaefer 2018). Differentiation of cellular compartments (Zakrzewski et al. 2019) allows formation of specific biological tissues and organs (Bryant and Mostov 2008). Each tissue and organ has a distinct internal environment and can help support the growth and survival of a macrocellular organism. Even within human society, each human can be considered to be compartmentalized within our own distinct bodies. While compartmentalization is a defining feature of life-a cell is a compartment, and all life requires cellsit is less clear how biological compartments came to exist in the first place.

\subsection{Historical context of primitive compartment research}

Around one century ago, Russian biochemist Alexander Oparin (1965) and British scientist J. B. S. Haldane (1929) independently introduced the first origin of life hypothesis in modern scientific history. Both scientists proposed a very similar scenario: the formation of the early reducing atmosphere on Earth, subsequent organic synthesis of primitive compounds, and assembly of these organic compounds into structures that could evolve, replicate, and sustain themselves energetically (Lazcano 2010; Tirard 2017). Incidentally, both models describe the first idea of prebiotic compartmentalization. Oparin and Haldane both suggested that organic molecules would be synthesized from inorganic carbon compounds triggered by UV irradiation, which would then settle and aggregate in the primeval ocean to form a 'prebiotic soup'. Oparin suggested that the first polymers resembling proteins and carbohydrates would assemble into colloidal particles, which would later develop a primitive metabolism akin to fermentation. He proposed that the colloidal particles would consume available nutrients through fermentation and develop photosynthesis after other nutrients became scarce. These particles are often referred to as 'coacervates', organic-rich droplets formed via LLPS. A specific class of coacervates, i.e., complex coacervates, result from the association of oppositely charged molecules. However, Oparin did not specifically identify that charged molecules played a role in the assembly of these particles. However, Haldane's idea of compartmentalization was slightly different from Oparin's. He suggested that abiotically formed macromolecules would instead serve as primitive membranes, a component of a compartment.

In the 1950s and 1960s, Sidney Fox, an American biochemist, described a putative protocell system that became a basis for the proteinoid theory of the origin of life (Fox and Harada 1958, 1960; Fox et al. 1959; Fox 1964, 1965). Fox showed that polymeric material formed upon thermal condensation of a mixture of amino acids assembled into microscopic spherules upon suspension in water. The microspherules exhibited interesting properties akin to cell reproduction, as they grew in an apparent accretion mechanism and then underwent 'budding' to eventually release smaller microspherules. The microspheres tended to assemble into long strands and resembled some of the earliest fossils found in ancient rocks. The proteinoids have additionally been shown to possess marginal catalytic properties towards hydrolysis reactions (Fox and Krampitz 1964; Oshima 1968; Quirk 2013). The scientific community has extensively criticized these studies of proteinoids due to unsubstantiated claims of non-random incorporation of amino acids into the polymeric material, linearity of the polymers, and, most outrageously, suggestions that proteinoids were alive. Proteinoid theory was largely dismissed and rarely revisited in the context of prebiotic chemistry. Despite the shortcomings of the proteinoid theory, it brought forward the idea of phase-separated systems playing a role in the origin of life (Fox 1976; Keating 2012).

A set of experiments related to proteinoid compartments was then conducted in the 1960s by the team of Krishna Bahadur, an Indian chemist (Bahadur 1967; Grote 2011; Gupta 2014). In a photochemical reaction, the team reported the formation of different variations of microspheres, dubbed 'Jeewanu' (Sanskrit for 'particles of life'), which were reported in a series of articles in the German journal Zentr. Bakteriol. Parasitenk. ((Bahadur 1964; Bahadur and Ranganayaki 1964; Bahadur et al. 1964) cited in (Grote 2011)) (figure 1). These compartments were synthesized by mixing inorganic nitrogenous (e.g., ammonium phosphate and ammonium molybdate) and organic (e.g., citric acid, ascorbic acid, paraformaldehyde, and formaldehyde) compounds with common biominerals from cells. Colloidal ferric chloride, molybdenum compounds, or other inorganics were also added due to their ability to act as catalysts or reaction cofactors. After a few days of sunlight exposure and shaking of the entire reaction mixture, microscopic spherical Jeewanu particles appeared. Bahadur claimed that the particles were enclosed by a semipermeable membrane and also 

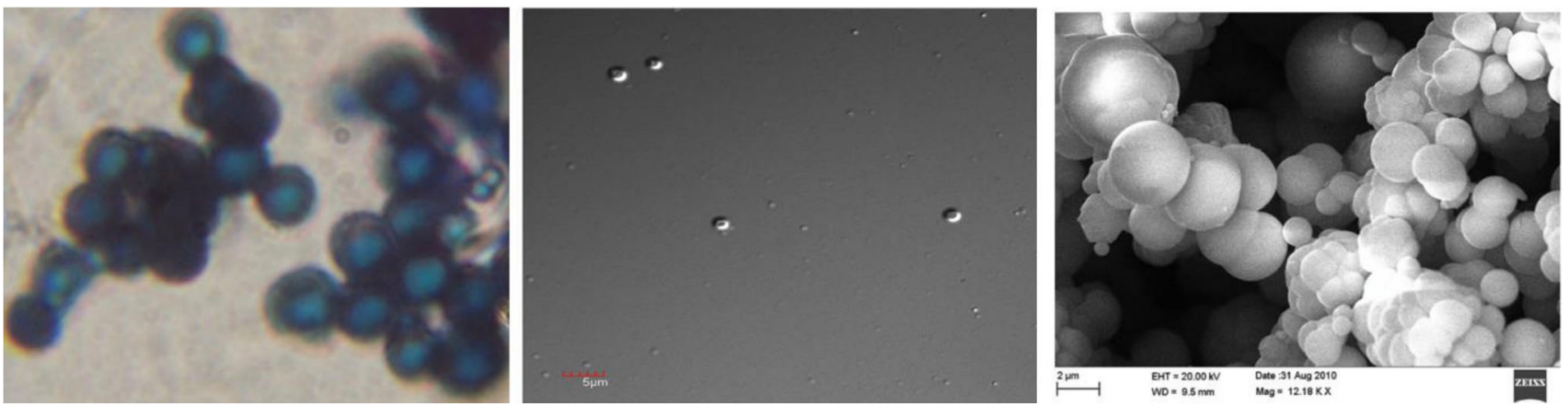

Figure 1. Jeewanu particles after 24 hours of sunlight exposure as observed by different microscopy methods. Left: Light microscopy. Middle: Confocal microscopy. Right: Scanning Electron Microscopy (SEM). Figures reproduced with permission from Gupta VK and Rai R K 2018 Cytochemical characterisation of photochemically formed, self-sustaining, abiogenic, protocell-like, supramolecular assemblies 'Jeewanu'. Int. J. Life Sci. 6(4):877-884 (Gupta and Rai 2018) under a Creative Commons License.

alleged Jeewanu's reproductive capability by budding, much like the process that single-celled organisms utilize for fission. Bahadur's later work on Jeewanu also detected the presence of peptides, sugars, and nucleobases synthesized within the compartments (Bahadur et al. 1977; Grote 2011). Bahadur's team changed the Jeewanu synthesis and workup protocols frequently, and their reports lacked in detail, so their experiments were difficult to reproduce. The scientific community largely dismissed Bahadur's work because of unsubstantiated claims that Jeewanu were alive (Grote 2011). However, through recent discussions and reexamination of Bahadur's original work, some researchers in the OoL field still consider Jeewanu to be a relevant and promising system of study (which was understudied and perhaps did not receive fair treatment) for understanding specific aspects of the origins of life (Gànti 2003; Gupta 2014). This example of a poorly studied, although likely relevant, system suggests that there may be a number of additional compartment systems beyond those studied widely that could contribute significantly to our understanding of primitive compartment function and evolution.

\subsection{Common primitive compartment model systems}

Since the initial studies mentioned above, a number of compartment systems have been explored in the context of primitive compartmentalization. One of the most widely studied systems are lipid bilayer membrane vesicles or liposomes (Luisi et al. 1999; Chen and Walde 2010). If we consider a very simplistic case, a modern cell is composed of a phospholipid membrane bilayer encapsulating heritable genetic information and biochemical reactions that allow the cell to maintain genetic replication, cell growth, and cell division (Alberts et al. 2007). Working backward in time, an ancient version of a cell would likely not have contained such complex biochemical reactions or structures that resulted from evolutionary processes taking place over billions of years. In particular, folded proteins are likely too complex to have existed in the earliest compartments on Earth and phospholipid synthesis may not have been plausible in the complex prebiotic milieu. As such, primitive vesicles are proposed to be composed of pure (Hargreaves and Deamer 1978) or mixtures (Jordan et al. 2019; Sarkar et al. 2020a) of fatty acids, which have been observed in meteorites (Kvenvolden 1974; Huang et al. 2005; Lai et al. 2019) or as products in prebiotic reactions (Allen and Ponnamperuma 1967; McCollom et al. 1999; Simoneit et al. 2007; Furukawa et al. 2008). Several reviews delve into the topic of lipid vesicles in the context of primitive compartments (Chen and Walde 2010; Schrum et al. 2010; Del Bianco and Mansy 2012; Deamer 2017; Wang and Szostak 2019; Sarkar et al. 2020b).

Recent OoL research has also resulted in a greater emphasis in studying other non-membrane-bound structures such as mineral pores/cavities/surfaces (Baaske et al. 2007; Cleaves et al. 2012; Hansma 2014; Kreysing et al. 2015; Westall et al. 2018; Gillams and Jia 2018) and membraneless phase-separated systems as primitive compartment models (Keating 2012; Mann 2012; Poudyal et al. 2018; Ghosh et al. 2020). The increase in interest and understanding of phase-separated compartments may be commensurate with the increase in understanding of the importance of modern 
membraneless organelles in biological processes (McSwiggen et al. 2019; Yoshizawa et al. 2020). Although it is plausible that some lipids could have been produced prebiotically, high and pure yields of complex lipids such as multiple-tail phospholipids would have been difficult to synthesize efficiently on early Earth due to the complexity of the prebiotic chemical milieu (Guttenberg et al. 2017). However, recent work has also shown the contribution and significance of diverse lipid mixtures in the assembly of primitive vesicle compartments (Jordan et al. 2019; Sarkar et al. 2020a), and thus existence of pure lipids on early Earth may not be so important. At the same time, it has been shown that prebiotically relevant polymers such as peptides (Campbell et al. 2019), depsipeptides (Forsythe et al. 2015; Yu et al. 2016; Frenkel-Pinter et al. 2021), or polyesters (Mamajanov et al. 2014; Chandru et al. 2018) could have been synthesized on early Earth, potentially through environmental effects such as wet-dry or temperature cycles. These products were likely to be mixtures of polymers containing polydisperse compositions such as a range of molecular weight, charge density/distribution, etc. Phase separation is a physical process that can occur under a variety of conditions, including in mixed/ polydisperse peptide and polyester systems (Koga et al. 2011; Jia et al. 2019), and thus phase separation has been proposed to be a plausible mechanism to assemble primitive compartments before the emergence of lipid membrane-bound compartments. As such, LLPS systems such as polyester microdroplets (Jia et al. 2019; Chandru et al. 2020b), coacervates (Ghosh et al. 2020), or ATPS (Keating 2012) have been widely used as primitive compartment model systems studied in laboratory-simulated prebiotic environments (figure 2) (Smith et al. 1967; Jia and Fraccia 2020; Fares et al. 2020). While depsipeptide compartments have not yet been explicitly shown in the laboratory, it is likely possible for these polymers to also form similar compartments due to their similarity in structure both to polyesters and peptides.

One additional point of interest in the OoL field is understanding whether membraneless droplets can contribute functions that could have aided in the evolution or function of primitive chemical systems. For example, LLPS can segregate catalytic molecules such as ribozymes or clay particles (Pir Cakmak and Keating 2017; Drobot et al. 2018). This may result in enhanced ribozyme catalysis through increases in local concentration or favorable chemical interactions (Poudyal et al. 2019a, b). Enhanced catalysis within such droplets could have helped to promote the synthesis of primitive biomolecules essential for evolution, including peptides, small molecules, or nucleic acids. Other observed primitive reactions within LLPS systems include replication of encapsulated genetic polymers (Mizuuchi and Ichihashi 2021) or simple chemical transformations catalyzed by encapsulated clay particles (Pir Cakmak and Keating 2017). In particular, the absence of a membrane results in the ability for analytes to cross the membraneless boundary of a membraneless droplet with lower energetic cost than crossing a membrane, as long as the analyte has chemical affinity and compatibility (charge, polarity, etc.) for the interior of the droplet (i.e., high enough partition coefficient, which will be discussed in more detail in a section below). This can be seen in the spontaneous multiple orders-of-magnitude increase in concentration of DNA within a DNA-peptide coacervate (Jia and Fraccia 2020) or of magnesium ions, nucleotides, and RNA within a polyamine/nucleotide coacervate (Frankel et al. 2016).

Certain LLPS systems can also interact with, scaffold, and/or segregate lipid vesicles, perhaps foreshadowing a transition from membraneless compartments to membrane-bound compartments at some point at the origins of life (Tang et al. 2014; Jia et al. 2014, 2019; Jing et al. 2019; Pir Cakmak et al. 2019; Lin et al. 2020). Other prebiotically relevant functions observed in phase-separated droplets include division (Yin et al. 2016; Zwicker et al. 2016), fusion (Jing et al. 2020), and protection of encapsulated molecules from degradation (Okihana and Ponnamperuma 1982; Zhao and Zacharia 2018), all of which could assist in evolution of a primitive compartment. While functions in primitive LLPS systems appear to be relatively simple compared to modern engineering applications, there are cases where functions or properties of primitive LLPS can be used in applied technologies. These will be discussed in the following sections.

\section{LLPS applied to biotechnology}

LLPS has been traditionally applied towards biotechnology and biomedical techniques due to their favorable properties such as differential partitioning, compartmentalization of biomolecules or cells (Shin et al. 2018; Mastiani et al. 2019), and biodegradability and biocompatibility (Chao and Shum 2020; Ma et al. 2020). Here, we present a few examples of LLPS applied to biomolecule purification and extraction and drug delivery. 
(a)

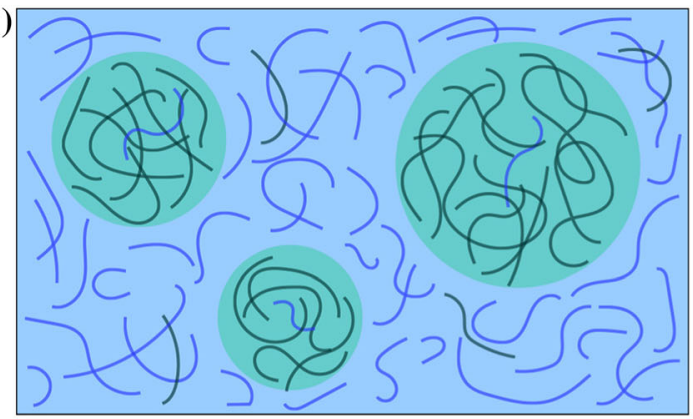

(c)

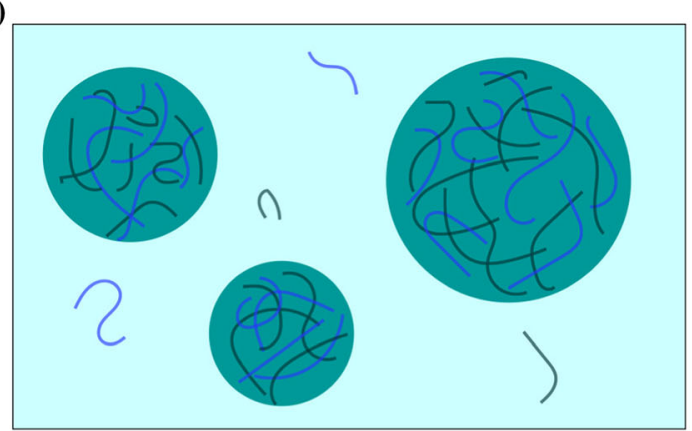

(b)

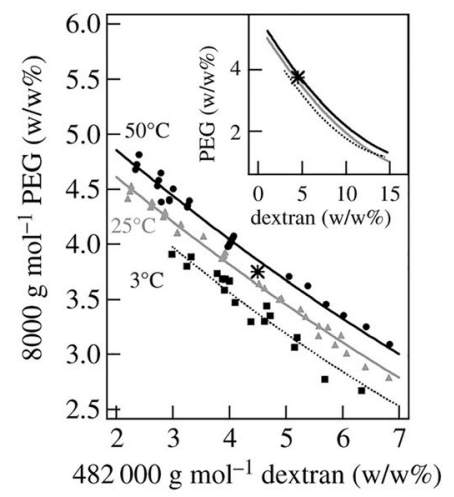

(d)

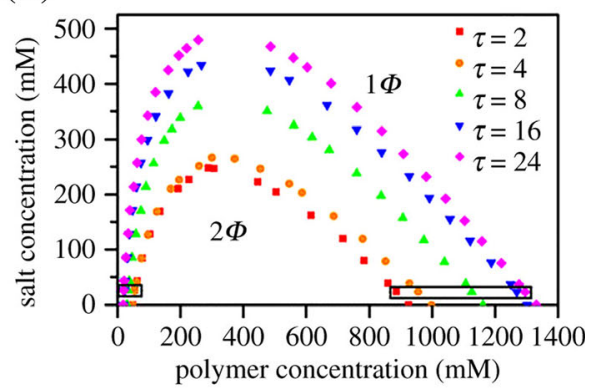

Figure 2. Formation of membraneless droplets through segregative (top; (a) and (b)), e.g. ATPS, and associative (bottom; (c) and (d)), e.g., complex coacervates, phase separation. In segregative phase separation, the polymers and molecules involved in the phase separation process are generally confined to separate phases (generally due to thermodynamic reasons). In associative phase separation, the polymers and molecules involved in the phase separation process generally interact and reside in the same condensed phase, with a dilute aqueous phase surrounding the concentrated droplet. Figures reproduced with permission from Crowe CD and Keating CD 2018 Liquid-liquid phase separation in artificial cells. Interface Focus 8(5):20180032 (Crowe and Keating 2018). Copyright The Royal Society 2018.

\subsection{Biomolecule purification and extraction}

LLPS systems inherently contain a different chemical environment from the surrounding aqueous solution, which is one of the reasons that phase separation occurs in the first place. Different LLPS systems also vary amongst themselves in terms of chemical environment. The subsequent affinities for various chemical compounds to partition into phase-separated droplets are highly dependent upon the chemical composition and character of both the LLPS system components and the partitioning chemical itself. For this reason, each molecule and LLPS system pair has a 'partition coefficient', which is a measure of the propensity of the biomolecule to segregate into the droplet compared to the surrounding solution (Iqbal et al. 2016). More specifically, the partition coefficient is the concentration of the given molecule within the droplet divided by the concentration of the given molecule outside of the droplet at equilibrium. The partition coefficient of various molecules in phase-separated systems has been investigated broadly (Albertsson 1986; Diamond and Hsu 1989; Iqbal et al. 2016), and recent studies have investigated this parameter in the context of primitive molecules and compartments (Keating 2012; Jia et al. 2014; Frankel et al. 2016; Jia and Fraccia 2020). As such, bioprocess researchers and engineers have utilized the differential partition coefficients of molecules in various LLPS systems as a means towards selective purification and extraction of biomolecules, a technique often used in industrial biomolecule synthesis.

Traditional molecular separation techniques utilizing ideas from organic chemistry may involve water-organic mixed-media separations, such as chromatography or extraction. While this process may be amenable for separation of organic molecules, biomolecules often have poor solubility or denature in such mixtures (especially in the organic phase), and thus traditional water-organic mixed-media purification/isolation processes can be quite inefficient (Mazzola et al. 2008; Benavides et al. 2011). However, LLPS often occurs between two purely aqueous phases, resulting in biomolecular partitioning without the need for an organic phase at all. As such, a number of the industrial systems used for biomolecule purification and extraction involve ATPS, which forms two immiscible liquid 
phases where biomolecules remain stable and do not immediately denature. Proteins are of particular interest in the ATPS biomolecule separation field due to their propensity to denature quickly in unamenable environments. Purification and extraction of a number of proteins using ATPS (Schütte 1997; Benavides et al. 2011; Khan et al. 2019), including enzymes (Mukherjee 2019) and antibodies (Rosa et al. 2009), has been demonstrated. However, there are still some limitations of applying ATPS to protein purification and extraction, such as low partition coefficients of proteins in ATPS. The concentration difference of a protein between the different phases in an ATPS is not high (Mazzola et al. 2008), and would lead to significant loss and efficiency issues during purification. However, optimization of separation parameters $(\mathrm{pH}$, salinity, temperature, etc.) or the use of novel techniques, such as the introduction of so-called system affinity ligands $(\mathrm{Ku}$ et al. 1989) or magnetic particles (Suzuki et al. 1995) with a high affinity towards the target protein into the system, have been used to improve protein purification efficiency.

The purification of biomolecules such as nucleic acids (Yau et al. 2015; McQueen and Lai 2019) by phase separation has also been demonstrated, although the utility of nucleic acid purification purely through phase separation is still unclear. In particular, the chemical diversity of nucleic acids is far lower than proteins, as there are four or five nucleotides of fairly similar chemical structure vs. the 20 or more amino acids that can be of quite a different chemical structure. As such, commercially available nucleic acid extraction and purification kits utilizing enzymes and spin columns often have sufficient efficiency for downstream purposes (Claassen et al. 2013; Becker et al. 2016). For example, some kits can limit the purified components to nucleic acids of a specific size (primitive systems on early Earth have also shown the ability to segregate nucleic acids by size (Mast et al. 2013)), while some kits can isolate nucleic acids of a specific strandedness (i.e., single-strands only). Additionally, because nucleic acid strands contain a string of bases, a very clearly defined complementary strand can also be used to identify, localize, and even isolate specific nucleic acid sequences from both in vitro and in vivo samples. Such 'pulldown' or 'hybridization' techniques have been applied to purify and isolate specific nucleic acids which are then subjected to further analysis such as sequencing (Licatalosi et al. 2008; Zhao et al. 2010; Tan et al. 2014). However, although specific nucleic sequences can be isolated by these techniques, the use of phase separation in combination with such techniques could afford further selectivity or efficiency and should continue to be explored. In particular, LLPS compartments have been suggested as potential mechanisms by which primitive systems can separate and sort primitive genetic materials (such as nucleic acids). As such, further developments from bioengineering of nucleic acid purification and extraction techniques that utilize phase separation would be of use for designing the next generation of nucleic acid purification techniques. For example, purification of plasmid DNA from crude E. coli lysate in an ATPS system (PEG-phosphate) resulted in a yield of $80-85 \%$ (Frerix et al. 2005). A similar PEG-phosphate ATPS system resulted in the separation of plasmid DNA from RNA (from a mixture containing only plasmid DNA and RNA) with yields of $89 \%$ (plasmid DNA) and 70\% (RNA), depending on pH (Frerix et al. 2006). These demonstrations suggest that with more optimization, LLPS could aid in both bulk/crude purification of nucleic acids as well as more fine purification of nucleic acids (such as separation of different types of nucleic acids). Such ideas/processes could also be of interest to those studying protocell genetic speciation in the origins of life field as well, as one mechanism of protocell genetic speciation would be through discriminate compartmentalization of different nucleic acid strands in different phase-separated compartments (Jia et al. 2021b).

\subsection{Drug delivery}

As mentioned previously, LLPS systems have a certain affinity for compartmentalizing specific molecules owing to their chemical properties and other added cosolutes. As such, phase-separated droplets have been applied to the compartmentalization of small molecule drugs and medicines, many of which are not readily soluble in aqueous solution (Johnson and Wang 2014; Dutta and Das 2015; Indulkar et al. 2016). However, this is not the only reason one may apply LLPS to drug delivery, as they provide a number of other favorable characteristics, such as drug protection and biodegradability. For example, researchers have reported a coacervate system coupled with sodium-alginate beads capable of protecting an encapsulated small molecule drug from low $\mathrm{pHs}$ caused by gastric juices, resulting in its release further downstream in the gastrointestinal tract (in the intestines) (Feng et al. 2014). Such a technique could be utilized to protect drugs from degradation before their intended delivery destination and can potentially increase the efficacy of 
the drug formulation without any chemical structural changes to the drug itself. Similarly, coacervates can afford protection to encapsulated proteins from temperature, $\mathrm{pH}$, and even denaturing solutions such as urea (Zhao and Zacharia 2018). In particular, Nojima, et al. utilized ionic surfactants to generate phase-separated protein condensates containing a high concentration of more than 600 different proteins while preserving their inherent structure (Nojima and Iyoda 2017; Nojima et al. 2019). Development of such technologies that form phase-separated droplets composed of multiple proteins, which themselves do not phase separate naturally, could help in the design of LLPS systems capable of transport of active protein cascades to specific locations in human patients. Therapeutic protein therapies have grown significantly in the recent few years; one such demonstration even utilized amylose-based coacervates to deliver functional myoglobin to human stem cells (figure 3) (Xiao et al. 2020). As such, the use of phase-separated protein complexes may become even more widespread as more efficient protein therapies are discovered (Lagassé et al. 2017), suggesting that application of LLPS to therapeutic protein delivery could be an important avenue of investigation going forward.

In particular, when subjecting a human or other living organism to drug delivery, the delivery vessel itself must also be safe. The vessel must either be degraded into harmless byproducts or eliminated/excreted through other natural means. A number of phase-separated systems afford safe biodegradability due to their composition, which results in their widespread use in such drug delivery applications. One type of phaseseparated drug delivery vessel that highlights this characteristic are polyester microspheres (Husmann et al. 2002; Mohamed and Van der Walle 2008), often composed of polylactate, polyglycolate, poly(lactate/ glycolate) co-polymers, or other aliphatic polyesters that can be charged with various small-molecule drugs (Ghalia and Dahman 2017; Washington et al. 2017; Karthick et al. 2019). These polymers are composed of simple aliphatic residues, and degrade into their monomer species (lactic acid and/or glycolic acid) through a simple hydrolysis mechanism. Upon degradation, lactic acid can be degraded safely by various natural processes such as neuron metabolism,

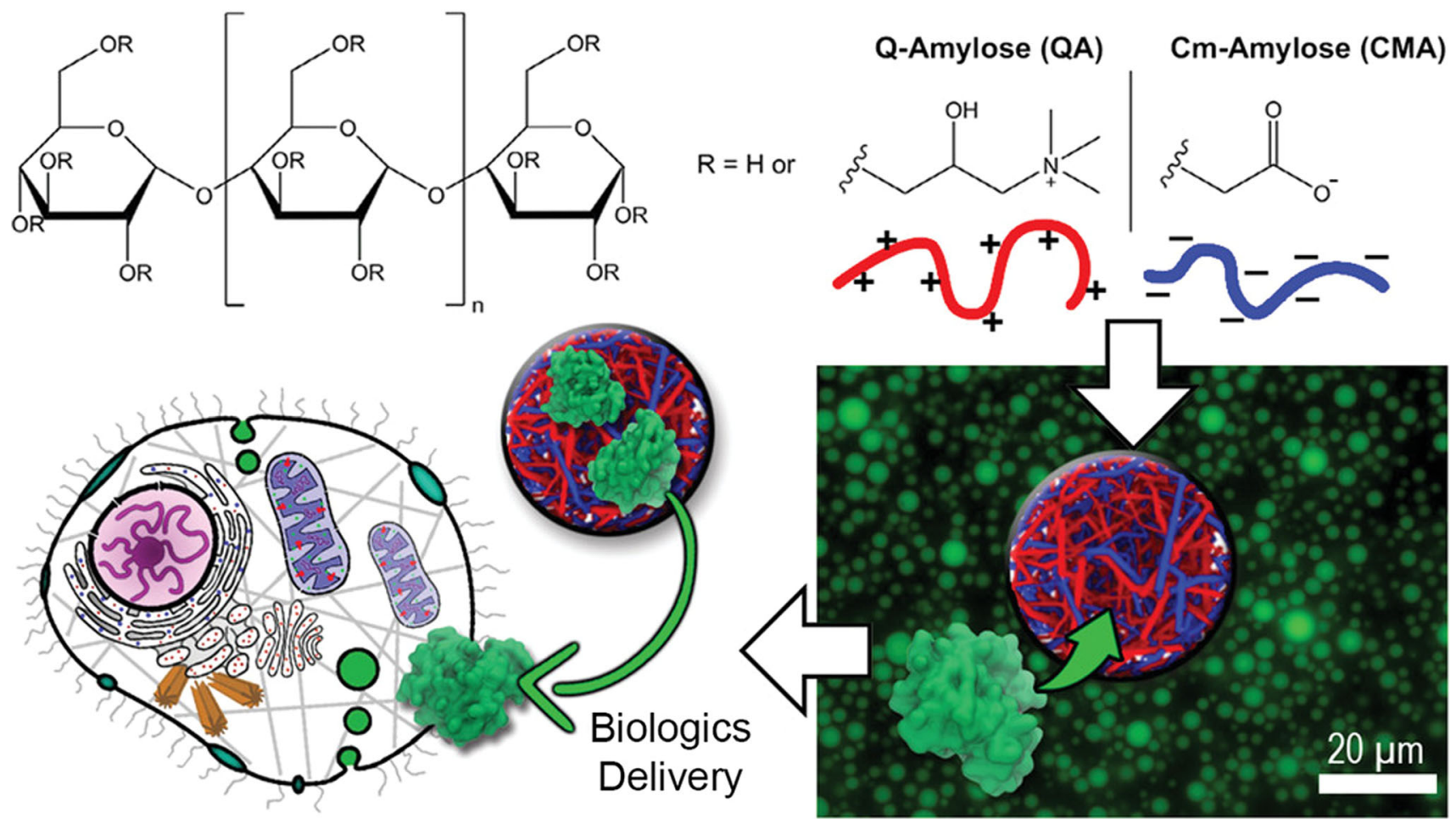

Figure 3. Use of amylose-based coacervates for protein therapy delivery to cells. Oppositely charged cationic Q-Amylose and anionic $\mathrm{Cm}$-Amylose polymers interact (top) to form a phase-separated coacervate (bottom right). This phase coacervate can then be loaded by protein therapies, such as myoglobin, to be delivered to specific cells, such as human stem cells. Figure reproduced with permission from Xiao W et al. 2020 Biopolymeric coacervate microvectors for the delivery of functional proteins to cells. Adv. Biosyst. 4(11):2000101 (Xiao et al. 2020) under a Creative Commons License. 
glucogenesis in the liver, oxidation to pyruvate in muscle cells, or excretion through urine or breath as carbon dioxide (da Silva D et al. 2018), suggesting the biocompatibility and biosafety of such polymers (Schakenraad and Dijkstra 1991). However, the degradation time of polyesters may be weeks or longer and also varies depending on a number of factors such as molecular weight, additives, and physical environment (such as $\mathrm{pH}$ and temperature), among other factors (Kopinke et al. 1996; Shive and Anderson 1997). Adverse or allergic reactions to polyesters and their byproducts have also been shown to occur in some situations (da Silva D et al. 2018). As such, new techniques to tune the degradation rate, such as addition of other polymers (Carvalho et al. 2020), novel polyester materials (like foams) (Mikos et al. 1994), or engineering of polyesters that can selectively degrade based on chosen external stimuli (Urbánek et al. 2019) are currently being explored.

Personalized genetic medicine such as DNA (Patil et al. 2005) or RNA (Dammes and Peer 2020) therapeutics, including miRNA (microRNA) (Avci and Baran 2014; Detassis et al. 2017) and siRNA (small interfering RNA) therapy (Hu et al. 2019, 2020), have been used as approved clinical treatments in recent years (Nair 2010; Horton and Lucassen 2019; Manolio et al. 2020). Additionally, recent interest in mRNA (Buschmann et al. 2021) and DNA-based vaccines (Silveira et al. 2021) has also increased, especially as mechanisms to inoculate the global population against the recent COVID-19 viral pandemic (Forni and Mantovani 2021). In particular, current mRNA vaccines against SARS-CoV-2 (the virus causing COVID19) utilize lipid particles (Mulligan et al. 2020; Jackson et al. 2020; Buschmann et al. 2021; Forni and Mantovani 2021) and current DNA vaccines against SARSCoV-2 utilize an adenovirus vector as delivery vessels (Feng et al. 2020; Ura et al. 2021). Various primitive LLPS systems have also shown the ability to harbor and/or concentrate nucleic acids (Frankel et al. 2016; Drobot et al. 2018; Jia and Fraccia 2020; Cakmak et al. 2020; Jia et al. 2021a), while recent work has begun focusing on stabilization of encapsulated viruses (as vaccine vectors) in coacervates (Mi et al. 2020). Perhaps incorporating LLPS systems as genetic carriers in future RNA or DNA vaccines could be an interesting direction of future study. However, while some studies probing the immune response of nanoparticles and other compartments as drug delivery vectors have been performed (Zolnik et al. 2010; Sutradhar and Amin 2013; Malachowski and Hassel 2020; Gagliardi et al. 2021), more work focusing on immune response of various LLPS systems must be completed to confirm the safety and efficacy of various LLPS systems before further pursuing novel LLPS systems as therapeutic delivery vectors (Jiskoot et al. 2009).

\section{LLPS applied to synthetic biology}

Synthetic biology is a broad field that includes goals such as engineering organisms or other biological constructs to perform certain functions. One sub-field in particular is the artificial cell field, which seeks to design or engineer cell-like compartments that exhibit life-like properties (such as metabolism, evolution, etc.) while not requiring an excess amount of energy input to maintain life. LLPS compartments have been proposed as primitive cell models and phase separation also produces membraneless organelles in modern organisms (Yoshizawa et al. 2020). As such, there is significant interest in use of LLPS within synthetic biology, especially with the recent major development of cell-free enzymatic systems and processes applied to synthetic biology (Lu 2017; Tinafar et al. 2019; Cho and $\mathrm{Lu}$ 2020). Here, we briefly review recent studies which seek to imbue biological processes into LLPS compartments and also discuss recent research utilizing phase separation in artificial cell construction.

\subsection{Biological processes imbued into LLPS systems}

Modern biology consists of a number of complex and fine-tuned biochemical processes which control various aspects of cellular function. For example, the classicalview central dogma of biology proposes biochemical processes which result in the expression of proteins starting from genetic information: replication of DNA, transcription from DNA to mRNA, and translation from mRNA to protein (Alberts et al. 2014) (although a number of recent studies have begun to reconsider the exact definition of the central dogma (Koonin 2012; Piras et al. 2012)). As such, there has been interest in observing biochemical processes in in vitro compartments, including those produced from phase separation, as a means to engineer more 'life-like' compartments in the laboratory.

In a recent study, Sokolova et al. produced coacervates from $E$. coli cell lysate and observed that transcription could still occur within the phase-separated coacervates (Sokolova et al. 2013). In fact, transcription rates increased within the coacervates as compared 
to within the lysate, potentially due to greater binding between DNA and RNA polymerase within the coacervates from concentration increases and crowding. Other studies have even proposed in vitro translation of various fluorescent RNA aptamers within coacervates (Deng 2020). Moving on from transcription, translation has also been studied within phase-separated compartments. Cell-free mRNA translation processes in PEG/dextran ATPS can occur unimpeded, and are of interest to large scale production of proteins in bioindustrial applications (Marszal et al. 1995). Targeted mRNA suppression and translation has also been observed to occur within a membraneless organelle inside eukaryotic cells (Reinkemeier et al. 2019). In fact, the possibility of in vitro gene expression (starting from DNA) of a fluorescent reporter protein within membraneless phase-separated coacervates has been reported, combining both transcription and translation processes in a concerted fashion (Tang et al. 2015). A recent study by Mizuuchi and Ichihashi further designed a PEG/dextran ATPS system within which mRNA could be translated into RNA polymerase, which would proceed to replicate its own coding mRNA (Mizuuchi and Ichihashi 2020). All of these aforementioned processes are complex and require a number of enzymes and other cofactors, but prebiotic biopolymerization processes likely took place in a nonenzymatic fashion. Researchers have thus reported coacervates which can also harbor non-enzymatic processes that can affect primitive nucleic acid replication and evolution such as nucleic acid polymerization (Poudyal et al. 2019a) or duplex melting (Nott et al. 2016), suggesting that even simple 'biology-like' processes can be encapsulated within phase-separated components.

Other than transcription and translation, other important biological processes have also been observed within phase-separated systems. For example, enzymatic cascades control a number of biosynthetic processes within cells (Walsh and Moore 2019) (including gene expression) and also have applications in biocatalysis (Sperl and Sieber 2018; Lee et al. 2021). In particular, living cells have been shown to utilize dynamic control of phase-separated structure assembly/ disassembly to segregate and organize successive enzymatic cascades depending on homeostatic reactions to various intracellular changes, as has been observed in yeast subjected to nutrient-depletion (Narayanaswamy et al. 2009) or in human cells subjected to high purine conditions (An et al. 2008). Such transient macromolecular associations of sequential enzymatic reactions, termed 'metabolons', control a variety of biological processes and have been widely studied in a number of biology fields (Nakashima et al. 2018; Sweetlove and Fernie 2018; Obata 2019; Zhang and Fernie 2021). As such, a number of research groups have taken natural metabolons as inspiration to design sequential enzymatic cascades within in vitro LLPS systems. Davis, et al. observed and modeled the activity of two sequential enzymes from a purine biosynthesis cascade (adenylosuccinate lyase and 5-aminoimidazole-4-carboxamide ribonucleotide transformylase/inosine monophosphate cyclohydrolase) within an ATPS (Davis et al. 2015). Utilizing techniques to produce compartments within compartments to separate enzymatic components, a number of research groups have also shown engineered enzymatic cascades within phase-separated systems. Kojima and Takayama showed that a glucose oxidase (GOx)horseradish peroxidase (HRP) cascade could proceed inside a coacervate-within-ATPS system, followed by a further dextranase step to disassemble the ATPS surrounding the coacervate (the dextranase actually preferentially resides within the coacervate phase) (figure 4) (Kojima and Takayama 2018). Chen, et al. then designed immiscible coacervate-in-coacervate droplets which could house an active GOx-HRP-catalase enzymatic cascade (Chen et al. 2020). Booth, et al. have also investigated a similar GOx-HRP cascade inside spatially separated coacervates within a proteinosome (although a proteinosome itself is not a phase-separated compartment) (Booth et al. 2019). These preceding three examples of enzymatic cascades were all performed within compartment-within-compartment systems. However, relevant life-like properties driven by protein networks observed in single compartment LLPS system, such as division, have also been observed (Song et al. 2018). Nevertheless, further study of enzymatic cascades or networks could be complemented by recent studies demonstrating a wide range of multiphase membraneless droplet systems (Mountain and Keating 2020, 2021; Lu and Spruijt 2020; Sato et al. 2020). These systems should be subjects of further study, perhaps even as a mechanism to show prebiotically relevant catalytic ribozyme cascades within a primitive compartment.

\subsection{Phase separation in artificial cell research}

One of the main goals of the artificial cell field is to design and demonstrate in vitro produced cell-like compartments with cell-like properties (Buddingh' and van Hest 2017; Beales et al. 2018; Martín et al. 2019), 
A
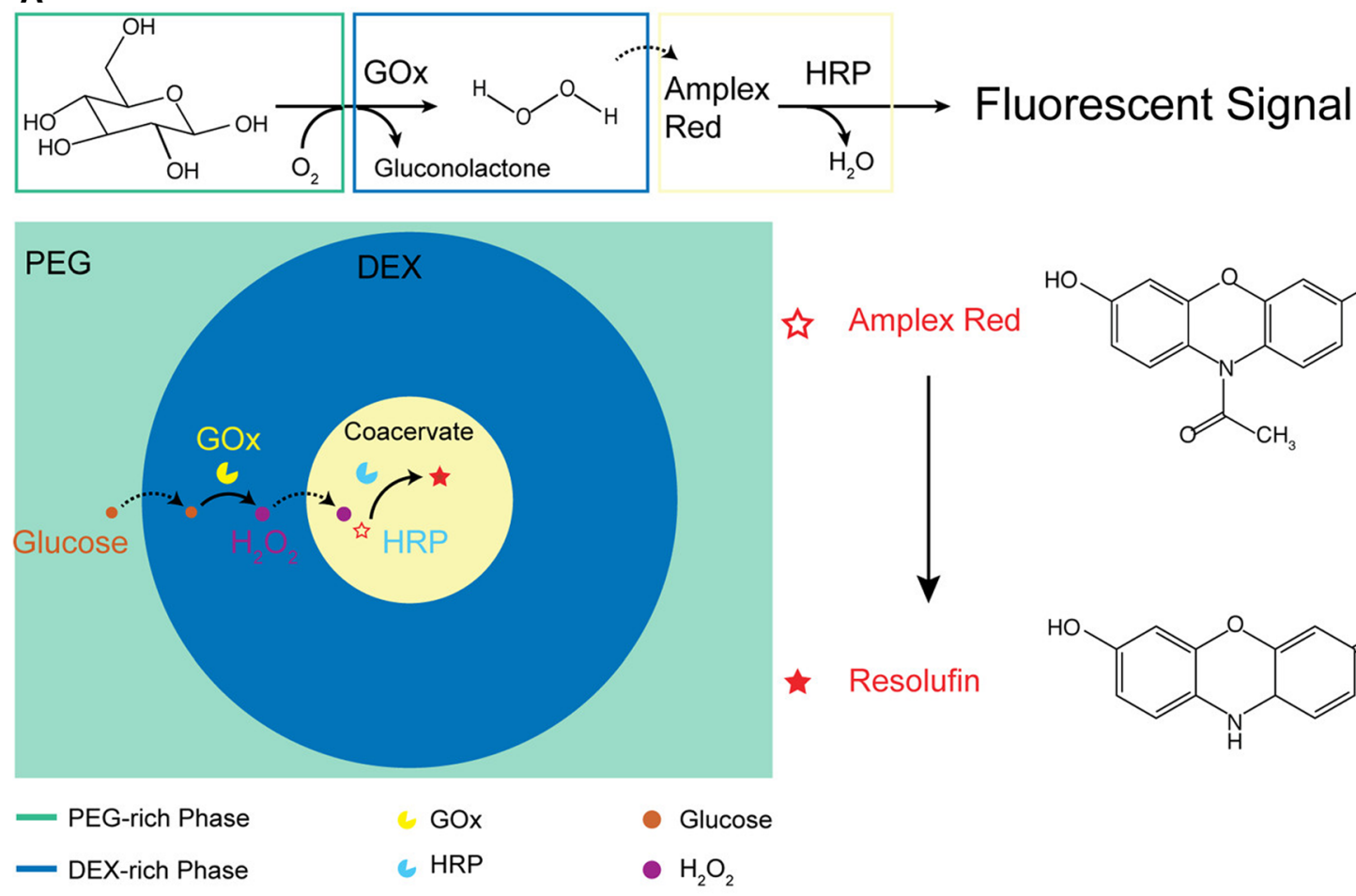

ATP-PDDA Coacervate

B
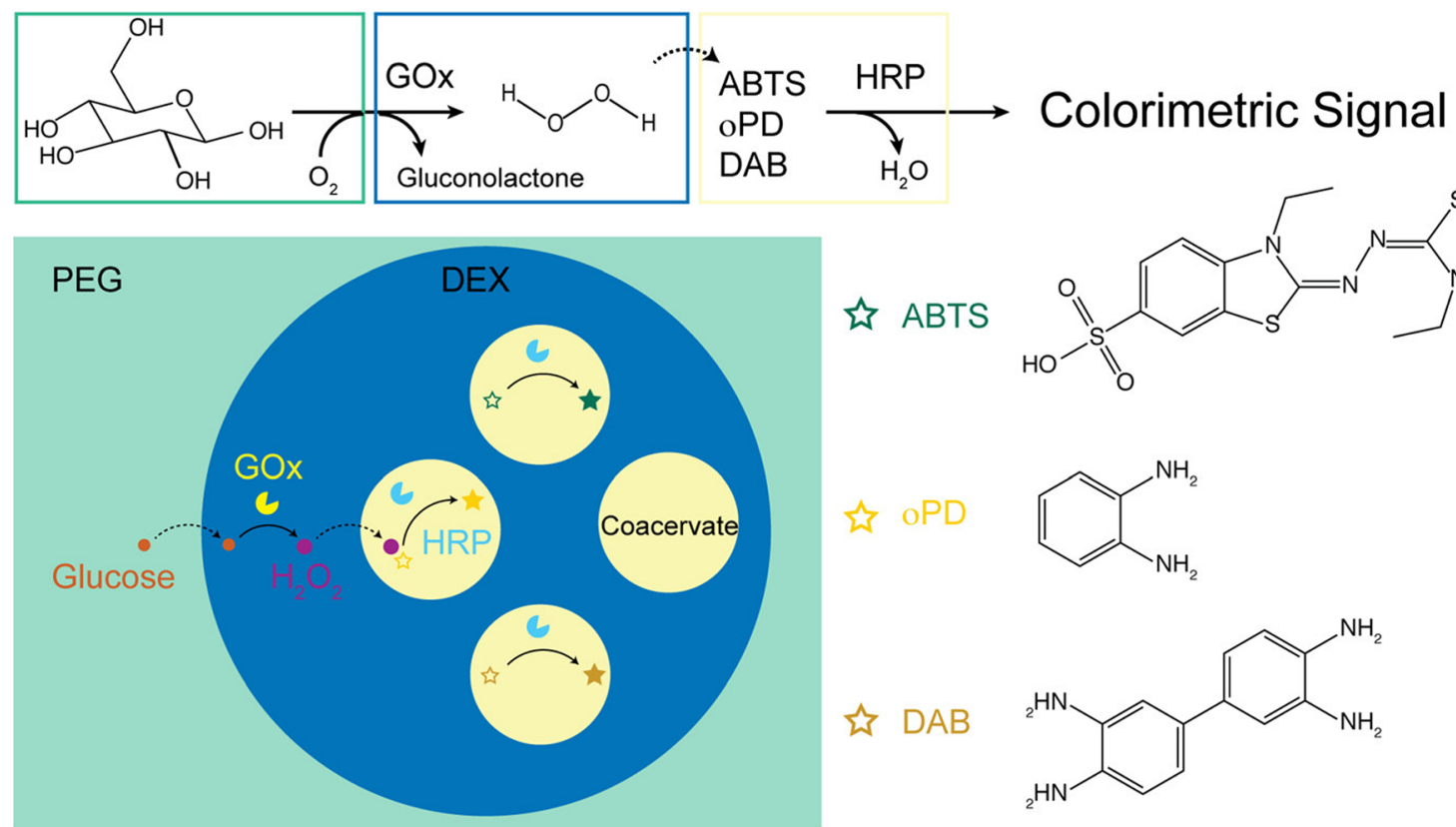

的 ABTS

Amplex Red<smiles>CC(=O)N1c2ccc(O)cc2Oc2cc(O)ccc21</smiles>

- Resolufin<smiles>O=C1C=CC2Nc3ccc(O)cc3OC2=C1</smiles><smiles>CCn1/c(=N/N=c2/sc3cc(S(=O)(=O)O)ccc3n2CC)sc2cc(S(=O)(=O)O)ccc21</smiles>

- PEG-rich Phase

GOx

- Glucose

- DEX-rich Phase

c HRP

- $\mathrm{H}_{2} \mathrm{O}_{2}$

ATP-PDDA Coacervate 
4Figure 4. An enzymatic cascade taking place within a coacervate-in-ATPS system. GOx first oxidizes glucose (originally in the PEG phase) within the dextran droplet to form hydrogen peroxide $\left(\mathrm{H}_{2} \mathrm{O}_{2}\right)$. The $\mathrm{H}_{2} \mathrm{O}_{2}$ then migrates into the coacervate phase (ATP-Poly(diallyldimethylammonium chloride)), and is used as an oxidating co-factor for HRP to oxidize an inactive reporter dye (Amplex Red, ABTS, oPD, or DAB) to its active fluorescent or colorometric form. Figure reproduced with permission from Kojima K and Takayama S 2018 Membraneless compartmentalization facilitates enzymatic cascade reactions and reduces substrate inhibition. ACS Appl. Mater. Interfaces 10(38):32782-32791 (Kojima and Takayama 2018). Copyright American Chemical Society 2018.

potentially for future application to modern engineering or bioengineering problems (Xu et al. 2016). To that end, a number of studies have proposed mechanisms to or demonstrated properties such as energy generation (Berhanu et al. 2019; Shin 2019; Jeong et al. 2020), metabolism (Sikkema et al. 2019), division (Steinkühler et al. 2020), regeneration (Lavickova et al. 2020), motility (Bartelt et al. 2018; Ghosh et al. 2019; Jeong et al. 2020), and/or homeostasis (Pols et al. 2019) within artificial cell systems. However, a selfreplicating or evolving artificial cell has yet to be demonstrated in the lab (Ding et al. 2014). Additionally, most current artificial cell research focuses on using liposomes, which is reasonable considering that liposomes are similar in structure to biological cells. As such, the incorporation of phase separation processes into artificial cell construction has not yet been explored to the full potential, despite the existence and importance of intracellular phase separation. Nevertheless, a number of very recent studies have utilized membraneless compartments generated from phase separation as artificial cell models (Martin 2019; Shang and Zhao 2021; van Stevendaal MHME et al. 2021).

Encapsulation or assembly of LLPS systems within liposomes or vesicles could result in the formation of an artificial cell with similarities to membraneless compartment-containing modern cells. For example, various aspects of the structure and function of a number of liposome-encapsulated LLPS systems have been studied (Helfrich et al. 2002; Long et al. 2005; Li et al. 2008; Crowe and Keating 2018; Liu et al. 2019; Love et al. 2020; Cakmak et al. 2021). While these studies share a common goal, they often differ in the construction of each system. Some studies have focused on utilizing microfluidics techniques to generate liposome-encapsulated LLPS systems, demonstrating the great effect that modern technological advances can have on construction and subsequent understanding of such encapsulated LLPS systems (Deng and Huck 2017; Deshpande et al. 2019; Jing et al. 2019; Ma et al. 2020). One particular study utilized a liposome system containing $\alpha$-hemolysin protein pores generated through a microfluidic platform. The pores allowed ATP from outside of the vesicle to flow into the vesicle system, where it could come into contact and complex with resident poly-L-lysine, forming coacervate droplets directly within a vesicle (figure 5). Other studies utilized chemical and environmental changes, such as $\mathrm{pH}$, to induce phase separation of encapsulated components of LLPS droplets within pre-assembled liposomes (Love et al. 2020; Last et al. 2020). Finally, direct assembly of lipid membrane constituents around pre-assembled phase-separated droplets, akin to LLPS-scaffolded membranes, has also been performed (Tang et al. 2014; Cakmak et al. 2021). In particular, the latter two techniques would have been quite relevant to primitive LLPS-in-vesicle systems, as environmental oscillations could lead to $\mathrm{pH}$ or temperature changes. Possible co-existence of precursors of lipids and membraneless compartment components such as nucleic acids and peptides have also been proposed to be plausible on early Earth (Patel et al. 2015). As such, further studies regarding LLPS systems as or within artificial cells could inform future studies of primitive compartment structure and function and vice-versa.

\section{LLPS applied to other engineering fields}

In addition to their use in the specific applied fields mentioned above, phase-separated systems also are used widely in other engineering fields due to their favorable characteristics. Some of these engineering applications utilize characteristics similar to those mentioned in above sections (i.e., encapsulation, biodegradability, etc.), while other uses of LLPS includes phase separation in biological systems to directly affect the surroundings. Here, we discuss and give examples from two specific engineering disciplines, pollution and waste control in environmental engineering and flavor encapsulation in food engineering, to further demonstrate the wide applicability of LLPS in the modern day. 
a
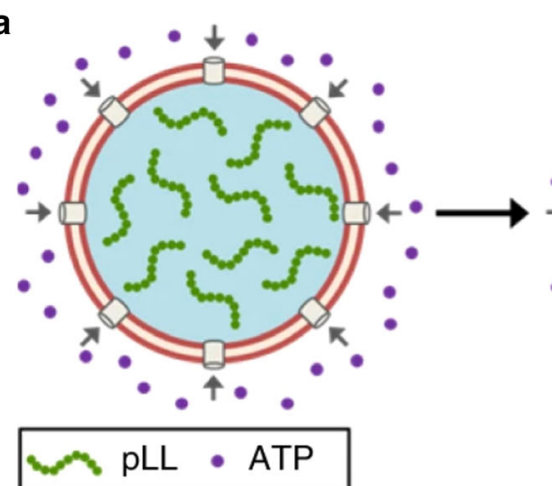

b
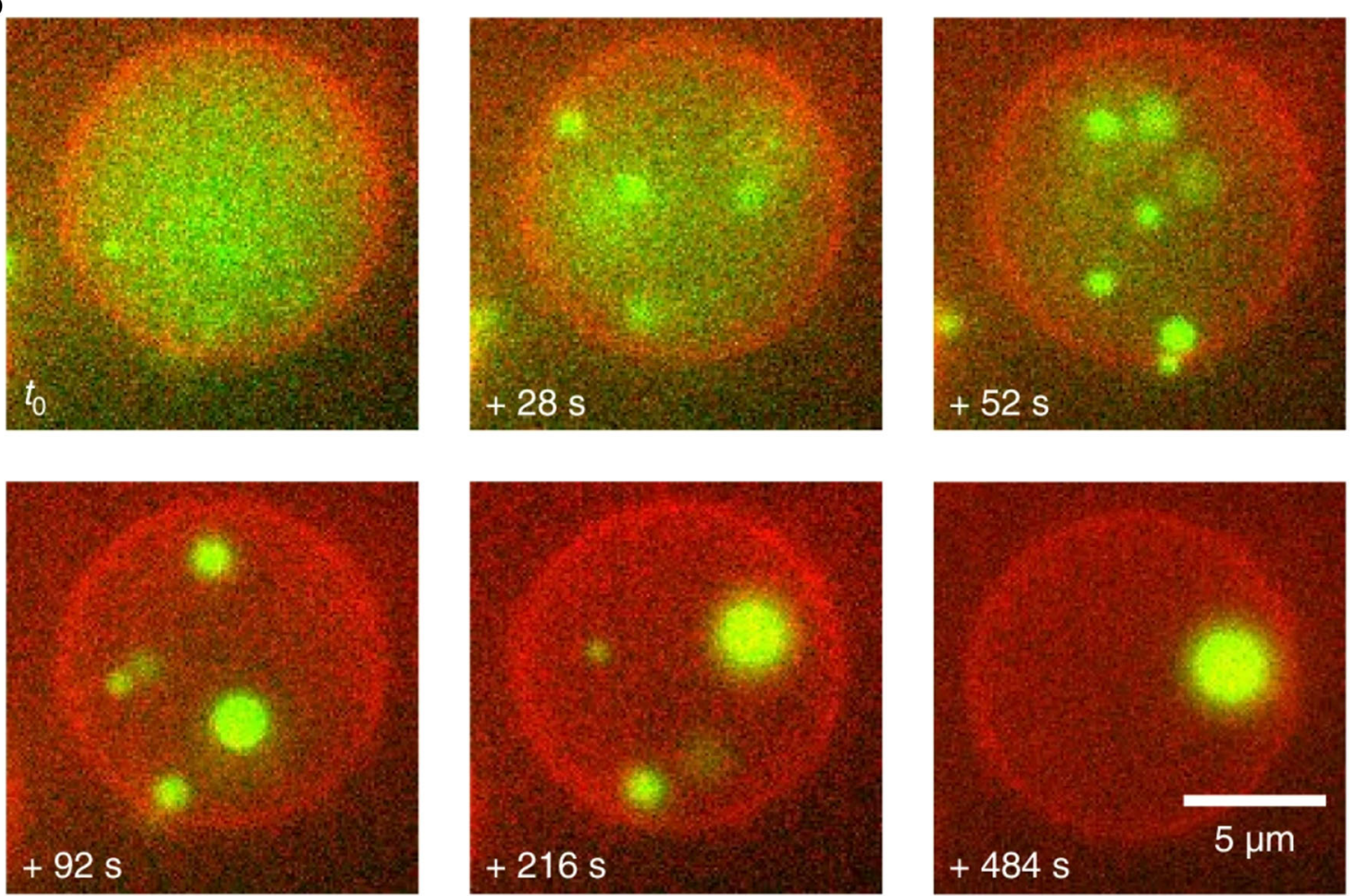

c
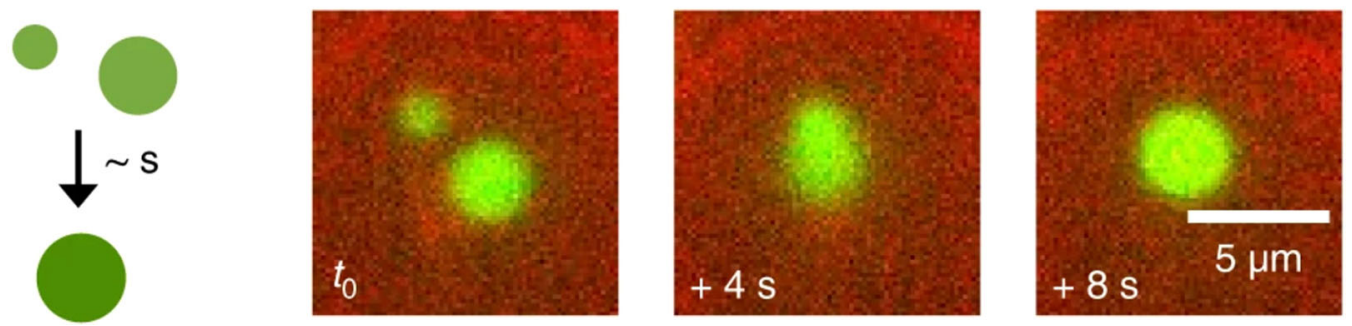

Figure 5. Formation of a coacervate within a liposome. (a) ATP flows into a liposome through $\alpha$-hemolysin pores, interacting and complexing with poly-L-lysine (pLL), phase separating to form a coacervate within the liposome. (b) Formation of the coacervate droplets (green) within a liposome over time. (c) Coalescence of two separate coacervate droplets within a liposome over time. An enzymatic cascade taking place within a coacervate-in-ATPS system. GOx first oxidizes glucose (originally in the PEG phase) within the dextran droplet to form hydrogen peroxide $\left(\mathrm{H}_{2} \mathrm{O}_{2}\right)$. The $\mathrm{H}_{2} \mathrm{O}_{2}$ then migrates into the coacervate phase (ATP-Poly(diallyldimethylammonium chloride)), and is used as an oxidating co-factor for HRP to oxidize an inactive reporter dye, Amplex Red, to its active fluorescent form (Resolufin). Figure reproduced with permission from Deshpande, S. 2019. 'Spatiotemporal control of coacervate formation within liposomes.' Nat. Commun. 10:1800 (Deshpande et al. 2019) under a Creative Commons License. 


\subsection{Waste and pollution control}

Chemical formulations of LLPS have been used towards waste and pollution control in environmental engineering, with increased recent interest. For example, ATPS are often used to recover precious components from industrial or biological waste due to their ability to selectively partition certain molecules. ATPS has been shown to assist in recovery of heavy metals from wastewater (Akama and Sali 2002; de Lemos LR et al. 2012; Hamta and Dehghani 2017) and proteins from fermentation (Porto et al. 2008), food (Antov et al. 2001), or industrial (Raja and Murty 2013) waste. Coacervates have also contributed to the removal of hazardous byproduct chemical dyes, plastics, and other small molecule organics (Luque et al. 2007; Zhao et al. 2017; Zhang et al. 2019; Valley et al. 2019) from industrial wastewater (figure 6). Such LLPS systems are of interest to environmental engineers as they can either be recycled or do not contribute to toxic waste (Raghavarao et al. 2003). For example, coacervates for use in chemical encapsulation have even been shown to be able to form from proteins extracted from leather waste (Ocak 2012).

In addition to chemically produced phase separation systems for waste and pollution control in environmental engineering, biological phase separation mechanisms are also used in waste and pollution control. As mentioned previously, membraneless droplets exist in most extant life. For example, bacteria and algae harbour intracellular phase-separated granules assembled from inorganic polyphosphate or different forms of polyhydroxyalkanoate (PHA) derivatives. These granules serve either as energy stock for longterm latency (Singh et al. 2013) or as virulence factors during the invasion of their hosts (Thewes et al. 2019); in Corynebacterium glutamicum, intracellular phosphate can accumulate to up to $0.6 \mathrm{M}$ (Lindner et al. $2007)$ ! In order to take advantage of the propensity of some microbes to incorporate external phosphates into internal phase-separated organelles, environmental scientists have employed such microbes to remove phosphorus from wastewater (Lindner et al. 2007; Bunce et al. 2018). After cell disruption, the polyphosphate-rich granules could then be separated from the aqueous phase using centrifugation in hot, basic water (1 M NaOH) (Eixler et al. 2005). Another similar case is the use of Enterobacter aerogenes to convert organics in domestic wastewater into intracellular polyhydroxybutyrate granules, a biodegradable plastic material (Afify et al. 2017).
In particular, both polyphosphates and PHAs are of interest to OoL researchers. Polyphosphates have been proposed to be prebiotic chaperones (Gray et al. 2014) as well as primitive bioenergy sources (Müller et al. 2019). However, there is still some uncertainty as to potential mechanisms by which inorganic phosphates such as polyphosphates could have plausibly been synthesized on early Earth (Keefe and Miller 1995), although some studies suggest volcanic production as a plausible mechanism (Yamagata et al. 1991). PHAs are biotically generated polyesters, and polyesters generated from $\alpha$ - hydroxyacids have been shown to form primitive compartments (Jia et al. 2019). Furthermore, combining and polyesters generated from $\beta$-hydroxyacids with polyphosphates resulted in the assembly of simple membrane pores (Das et al. 1997), suggesting a combination of PHAs and polyP in the future may yield structures of interest both to OoL researchers and to engineers of a variety of fields.

\subsection{LLPS in food industry}

Phase separation is a common characteristic of many natural and processed foods and beverages, and encompasses combinations of coexisting gas, liquid, and solid states of matter. Gas and solid or liquid states coexist in whipped cream, culinary foams, and bread; milk and coffee feature particles suspended in a liquid; and butter and chocolate are solid-solid separated systems (Tolstoguzov 2000). For the purposes of this review, we concentrate on water/water $(\mathrm{W} / \mathrm{W})$ emulsions in food items associated with polymer incompatibility and biopolymer-driven coacervation. The thermodynamic incompatibility of biopolymers was first observed and documented over a hundred years ago, when Beijerinck discovered the immiscibility of aqueous solutions of gelatin and agar (Beijerinck 1910). Upon mixing, the two solutions formed W/W emulsions in which the gelatin solution became suspended in the continuous agar solution phase, or vice versa. The thermodynamic incompatibility of biopolymers is one mechanism to drive phase separation in food systems. Alternatively, LLPS in food-related systems can also occur in aqueous solution of oppositely charged biopolymers, such as proteins and polysaccharides. As a result of LLPS, the polyion mixture splits into two distinct phases: a dense coacervate phase, which is relatively concentrated in the polyions, and a dilute equilibrium phase (Burgess 1990). 
(a)

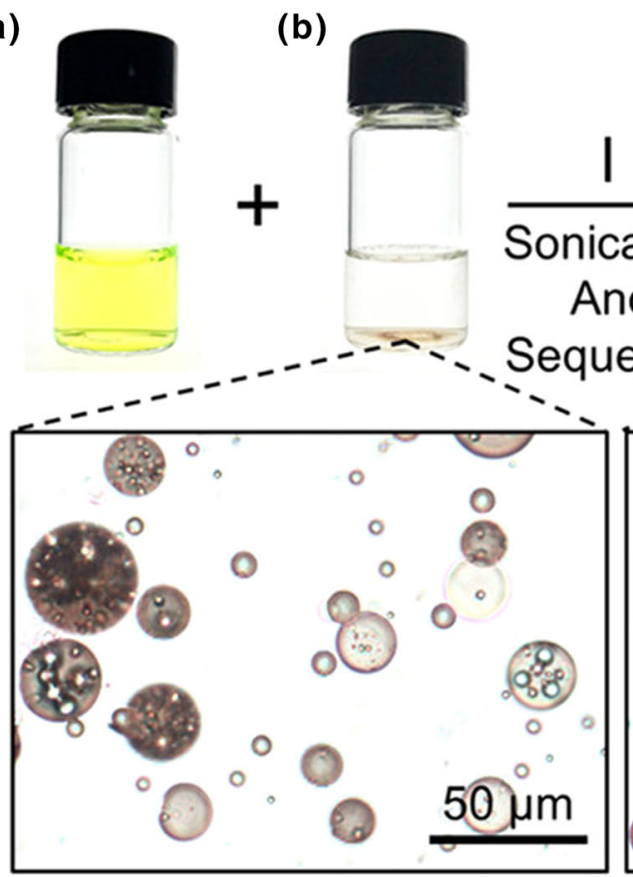

Simple Coacervates (c)

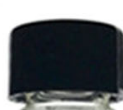

(d)

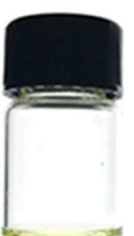

\section{And}
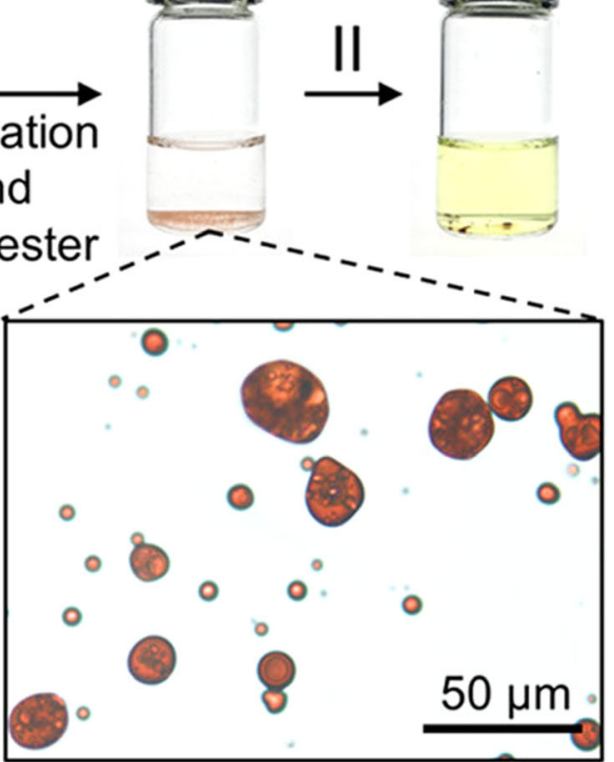

Flu-Loaded Coacervates

\section{(e) Base-Driven Intra-Coacervate Radical Cation Formation}
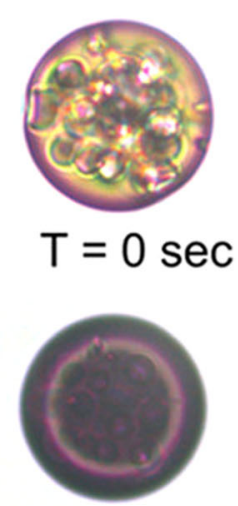

$\mathrm{T}=120 \mathrm{sec}$

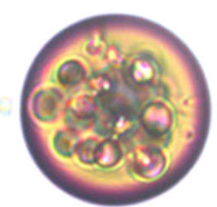

$\mathrm{T}=30 \mathrm{sec}$

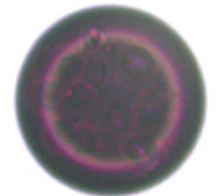

$\mathrm{T}=140 \mathrm{sec}$

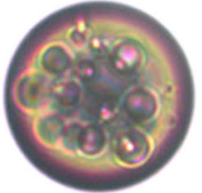

$\mathrm{T}=60 \mathrm{sec}$

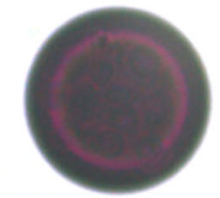

$\mathrm{T}=160 \mathrm{sec}$

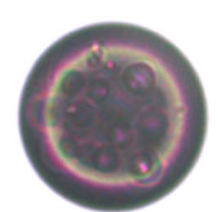

$\mathrm{T}=100 \mathrm{sec}$

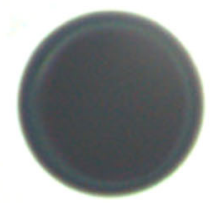

$\mathrm{T}=180 \mathrm{sec}$

\section{$25 \mu \mathrm{m}$}

Figure 6. Sequestration of fluorescein dye within a bipyridinium-functionalized poly-lipoic ester (BPLE) coacervate through sonication. (a) Fluorescein in solution, as visible by the yellow hue. (b) BPLE coacervate droplets in solution (bottom left micrograph). (c) After combining the coacervates and fluorescein, sonication results in fluorescein becoming sequestered within the droplets (bottom right micrograph). (d) Addition of acetic acid to the fluorescein-loaded coacervates results in release of fluorescein back into solution, as visible by the off-yellow hue. (e) Coacervates exposed to $\mathrm{pH} 14$ conditions results in rapid formation of radical cations within the droplets, as observed by the coacervates changing to a violet color over time. Figure reproduced with permission from Zhang Z et al. 2019 Poly-lipoic ester-based coacervates for the efficient removal of organic pollutants from water and increased point-of-use versatility. Chem. Mater. 31(12):4405-4417 (Zhang et al. 2019). Copyright American Chemical Society 2019.

The microstructure of food has been shown to impact the sensory and textural properties of food and its digestion. Utilization of various processing methods, combinations of macronutrients, and ingredients allow for the design of foods with different microstructures associated with novel sensory and functional properties 
(Norton et al. 2015). One of the main applications of LLPS is to achieve desired textures in food products. LLPS results in the formation of W/W emulsions with biopolymers disproportionately distributed between separated liquid phases. The difference in biopolymer hydrophilicity and molecular weights results in water redistribution between the coexisting phases that results in the gelation of one or more phases, affecting the emulsion's rheological properties (Tolstoguzov 2006). The texture of the W/W emulsion can be further manipulated by shear treatments, e.g., mixing, stirring, homogenization, or extrusion (Tolstoguzov 1993; Juttulapa et al. 2017). The dispersed phase of the $\mathrm{W} / \mathrm{W}$ emulsion undergoes deformation and coalescence to take the form of liquid fibrils or lamellae associated with firmer texture (Tolstoguzov 1987). Texturization can be further achieved by altering the physical state of water. For example, freezing has been long utilized in producing a firm variety of tofu termed koya-dofu. A uniform fibrous protein structure is formed during freezing of the tofu prompted by concentration and gelation of the protein phase between ice crystals (Tanaka 2012).

Additionally, driven by health and nutrition concerns, the modern food industry also strives to invent healthier products or to redesign existing products to maximize their nutritional value. The challenge becomes putting forward healthier food items that contain reduced amounts of fat, carbohydrates, and salt, are fortified with essential vitamins and minerals, and formulated to improve digestion and suppress appetite, all while without sacrificing the flavor or texture (Wu et al. 2014). In particular, phase separation and the properties of the compartments generated (e.g., encapsulation or exclusion of specific molecules such as fats, salts, or vitamins) is one mechanism by which some of these challenges can be met. Carbohydrate or protein-based LLPS is commonly used to encapsulate active ingredients within the dispersed phase. The encapsulation accomplishes multiple functions in food products including masking unpleasant flavors, stabilizing reactive ingredients, and controlling the release of active compounds. Multiple encapsulations by coacervation systems are either already in use or under investigation (Eghbal and Choudhary 2018). For example, encapsulation provides a means of introducing polyphenols into food products without sacrificing taste. Nutritional polyphenols have multiple health benefits but are associated with a bitter taste and an astringent mouthfeel (Jöbstl et al. 2004). Encapsulation of (-)-epigallocatechin-3-gallate (ECCG) in $\beta$-Lactoglobulin particles dramatically suppressed the astringency and bitterness of polyphenol compounds (Shpigelman et al. 2012). Ufeduba and Akoh (Ifeduba and Akoh 2015) also demonstrated that encapsulation of stearidonic acid soybean oil in gelatin/gum arabic coacervates modified by the Maillard reaction achieved high oxidative stability in fortified yogurt formulations. Finally, similar to drug delivery systems mentioned above, phase separated gels and coacervates are under consideration for the manufacturing of control release systems in food engineering. The release of encapsulated agents is triggered by the change in $\mathrm{pH}$, temperature, or response to enzymatic degradation (Chen et al. 2006). Rutz et al. (2017) recently demonstrated the formation of stable encapsulation of palm oil in chitosan/pectin and chitosan/xanthan gum particles; the release of the palm oil was then readily achieved in simulated gastrointestinal fluid.

In summary, LLPS employing biopolymers, such as proteins and polysaccharides in water solutions, provides a versatile set of tools for the formulation of foods with a variety of textures, flavors, and nutritional values in addition to providing nutraceutical delivery platforms. These properties of food are met partially due to various LLPS properties, some of which mirror properties relevant to the other applications mentioned in this paper and the OoL field as well. For example, preferential encapsulation in and timed release of specific components of LLPS droplets can be readily applied to drug delivery as well as to evolving protocell models. Additionally, similar mechanisms to modulate texture and rheology by LLPS in food science could be also relevant to modulation of primitive compartment rheologies. A gel-like state could be undesirable for a primitive compartment due to the resulting potential changes in analyte solubility and diffusion rate upon gelation (Mamajanov 2019). However, in other cases, a gel-like state could actually be desirable due to potential confinement/exclusion properties and its existence as an alternative medium (Trevors and Pollack 2005; Dass et al. 2018).

\section{Conclusions and future directions}

Here, we have presented an overview of compartment research in the field of origins of life, briefly highlighting primitive compartments generated from phase separation including coacervates and ATPS. These primitive LLPS systems also exhibit certain functions that could have promoted the function or evolution of primitive compartments. Although these functions may seem simplistic compared to those of highly engineered 
LLPS systems used in modern-day applications, there is still some potential for OoL research focusing on primitive LLPS to inform engineering research of applied LLPS technologies and vice-versa. As such, we presented a survey of some LLPS systems applied to various applied or engineering fields, including bioengineering, synthetic biology, environmental engineering, and food science, as a means to start discussions between researchers in applied LLPS research and fundamental LLPS research in particular origins of life researchers. However, this review contained only a brief overview of the large expanse of applied LLPS systems, and we encourage OoL researchers to further explore functions of other applied LLPS systems as a way to consider additional prebiotically relevant functions that could have been present on early Earth. Similarly, we encourage researchers studying LLPS systems in the context of engineering applications to look further into research on primitive LLPS system functions to potentially be inspired to incorporate such simple yet essential functions into modern LLPS systems used in various engineering fields. In particular, we note that the artificial cell field may be a perfect place to start for both origins of life and engineering fields due to its interdisciplinarity, as artificial cell research has roots in both primitive compartment/protocell research as well as in synthetic biology.

There are also a number of other LLPS systems not covered in depth in this review (i.e., non-ATPS and non-coacervate systems) used in engineering that can be applied to origins of life research. We have mentioned briefly the prevalence of polyester droplets used in drug delivery (Husmann et al. 2002; Mohamed and Van der Walle 2008). These droplets can be applied towards studying primitive membraneless polyesterbased protocells (Jia et al. 2019, 2021a; Chandru et al. 2020b). Additionally, water-in-oil or oil-in-water emulsions are often used in food science to generate new textures (similar to the W/W emulsions mentioned above) (Muschiolik and Dickinson 2017; Zhu et al. 2019; Zembyla et al. 2020), as well as in emulsion polymerase chain reaction, which is a technique for amplification of small amounts of nucleic acids for sequencing (Shao et al. 2011; Kanagal-Shamanna 2016). Such oil-in-water or water-in-oil droplet systems have been used in OoL research to study primitive replication and evolution in protocell systems (Gutierrez et al. 2014; Bansho et al. 2016; Mizuuchi and Ichihashi 2018, 2021; Furubayashi et al. 2020). Supercritical fluids, such as supercritical carbon dioxide, are also used in chemical separation and purification (Lucien et al. 1993; Díaz-Reinoso et al. 2006; Manjare and Dhingra 2019), and the existence of a supercritical carbon dioxide phase at the bottom of ocean ridges (high pressure zones) has been studied in the context of primitive compartment formation (Mayer et al. 2015), biomolecular selection (Mayer et al. 2017), and alternative solvents for prebiotic reactions (Budisa and Schulze-Makuch 2014). Thus, based on the clear connections between origins of life research and applied fields presented herein, we hope that new and fruitful collaborations between researchers studying all facets of LLPS can then be seeded going forward.

\section{Acknowledgements}

The authors thank Prof. Sudha Rajamani (IISER-Pune) for helpful discussions and feedback regarding this manuscript. T.Z.J. also thanks Prof. Rajamani and all other organizers of the Phase Separation in the Nucleus virtual meeting in 2021 for the opportunity to speak and also for the invitation to submit this article for consideration in the current special issue of Journal of Biosciences. T.Z.J. and I.M are supported by project grants from the Astrobiology Center Program of Japan National Institutes of Natural Sciences (NINS) (Grant Number AB311021, AB021008). T.Z.J. is further supported by Japan Society for the Promotion of Science (JSPS) Grants-in-aid 18K14354 and 21K14746, a Tokyo Institute of Technology Yoshinori Ohsumi Fund for Fundamental Research, and by the Assistant Staffing Program by the Gender Equality Section, Diversity Promotion Office, Tokyo Institute of Technology. P.-H.W. is supported by the Ministry of Science and Technology of Taiwan (MOST 110-2222-E-008002). T.N. is supported by JSPS Grant-in-aid 20K06519. I.M is supported by JSPS Grant-in-aid 21K03735. T.Z.J. and I.M. are researchers at (and P.H.W. is an affiliate of) the Earth-Life Science Institute (ELSI) of the Tokyo Institute of Technology, which is sponsored by a grant from the Japan Ministry of Education, Culture, Sports, Science and Technology as part of the World Premier International Research Center Initiative (WPI).

\section{References}

Abbas M, Lipiński WP, Wang J and Spruijt E 2021 Peptidebased coacervates as biomimetic protocells. Chem. Soc. Rev. 50 3690-3705 
Afify A, Gwad EL and AA, and EL Rahman NA, 2017 Using Enterobacter aerogenes DSM 30053 for biohydrogen production by microbial electrolysis cells from domestic wastewater. J. Agric. Chem. Biotech. 8 167-171

Akama Y and Sali A 2002 Extraction mechanism of Cr(VI) on the aqueous two-phase system of tetrabutylammonium bromide and $(\mathrm{NH}(4))(2) \mathrm{SO}(4)$ mixture. Talanta 57 681-686

Alberts B, Johnson AD, Lewis J, Morgan D, Raff M, Roberts K and Walter P 2014 Molecular biology of the cell: sixth international student (New York: W.W. Norton \& Company)

Alberts B, Johnson A, Lewis J, Raff M, Roberts K, and Walter P 2007 Molecular biology of the cell (New York: Garland Science)

Albertsson P-A 1986 Partition of cell particles and macromolecules (Hoboken: Wiley)

Allen WV and Ponnamperuma C 1967 Possible prebiotic synthesis of monocarboxylic acids. Curr. Mod. Biol. 1 24-28

An S, Kumar R, Sheets ED and Benkovic SJ 2008 Reversible Compartmentalization of de novo purine biosynthetic complexes in living cells. Science $\mathbf{3 2 0}$ 103-106

Antov MG, Peričin DM and Dimić GR 2001 Cultivation of Polyporus squamosus for pectinase production in aqueous two-phase system containing sugar beet extraction waste. J. Biotechnol. 91 83-87

Avci CB and Baran Y 2014 Use of microRNAs in personalized medicine. Methods Mol. Biol. 1107 311-325

Baaske P, Weinert FM, Duhr S, Lemke KH, Russell MJ and Braun D 2007 Extreme accumulation of nucleotides in simulated hydrothermal pore systems. Proc. Natl. Acad. Sci. USA 104 9346-9351

Bahadur K 1964 Synthesis of Jeewanu, the units capable of growth, multiplication and metabolic activity. III. Preparation of microspheres capable of growth and division by budding and having metabolic activity with peptides prepared thermally. Zentr. Bakteriol. Parasitenk. 117 585-602

Bahadur K, et al. 1964 Synthesis of Jeewanu, the units capable of growth, multiplication and metabolic activity. II. Photochemical preparation of growing and multiplying units with metabolic activities. Zentr. Bakteriol. Parasitenk. 117 575-584

Bahadur K 1967 Synthesis of Jeewanu, the protocell. Zentr. Bakteriol. Parasitenk. 121 291-319

Bahadur K, Kumar S and Gusain PS 1977 Effect of tetracycline on the formation of nucleic acid bases formed in photochemically synthesized micro-structure, called "Jeewanu." Zentr. Bakteriol. Parasitenk. 132 666-672

Bahadur K and Ranganayaki S 1964 Synthesis of Jeewanu, the units capable of growth, multiplication and metabolic activity. I. Preparation of units capable of growth and division and having metabolic activity. Zentr. Bakteriol. Parasitenk. 117 567-574

Bansho Y, Furubayashi T, Ichihashi N and Yomo T 2016 Host-parasite oscillation dynamics and evolution in a compartmentalized RNA replication system. Proc. Natl. Acad. Sci. USA 113 4045-4050

Bartelt SM, Steinkühler J, Dimova R and Wegner SV 2018 Light-guided motility of a minimal synthetic cell. Nano Lett. 18 7268-7274

Beales PA, Ciani B and Mann S 2018 The artificial cell: biology-inspired compartmentalization of chemical function. Interface Focus 820180046

Becker L, Steglich M, Fuchs S, Werner G and Nübel U 2016 Comparison of six commercial kits to extract bacterial chromosome and plasmid DNA for MiSeq sequencing. Sci. Rep. 628063

Beijerinck MW 1910 On the emulsion formation during mixing of aqueous solutions of certain colloids gelatinierender (in German). Zeitsch. Chem. Ind. Kolloide 7 16-20

Benavides J, Rito-Palomares M, and Asenjo JA 2011 Aqueous two-phase systems; in: Comprehensive biotechnology (ed) M Moo-Young (Amsterdam, NL: Elsevier) pp 697-713

Benner SA, Kim H-J and Biondi E 2019 Prebiotic chemistry that could not not have happened. Life 984

Berhanu S, Ueda T and Kuruma Y 2019 Artificial photosynthetic cell producing energy for protein synthesis. Nat. Commun. 101325

Boeynaems S, et al. 2018 Protein phase separation: a new phase in cell biology. Trends Cell Biol. 28 420-435

Booth R, Qiao Y, Li M and Mann S 2019 Spatial positioning and chemical coupling in coacervate-in-proteinosome protocells. Angew. Chem. Int. Ed. Engl. 58 9120-9124

Bruylants G, Bartik K and Reisse J 2011 Prebiotic chemistry: a fuzzy field. C. R. Chim. 14 388-391

Bryant DM and Mostov KE 2008 From cells to organs: building polarized tissue. Nat. Rev. Mol. Cell Biol. 9 887-901

Buddingh' BC and Hest JCM van 2017 Artificial cells: synthetic compartments with life-like functionality and adaptivity. Acc. Chem. Res. 50 769-777

Budisa N and Schulze-Makuch D 2014 Supercritical carbon dioxide and its potential as a life-sustaining solvent in a planetary environment. Life 4 331-340

Bunce JT, Ndam E, Ofiteru ID, Moore A and Graham DW 2018 A review of phosphorus removal technologies and their applicability to small-scale domestic wastewater treatment systems. Front. Environ. Sci. 68

Burgess DJ 1990 Practical analysis of complex coacervate systems. J. Colloid Interface Sci. 140 227-238

Buschmann MD, Carrasco MJ, Alishetty S, Paige M, Alameh MG and Weissman D 2021 Nanomaterial delivery systems for mRNA vaccines. Vaccines $\mathbf{9} 65$ 
Butch CJ, Meringer M, Gagnon J-S and Cleaves HJ 2021 Open questions in understanding life's origins. Commun. Chem. 411

Cakmak FP, Choi S, Meyer MO, Bevilacqua PC and Keating CD 2020 Prebiotically-relevant low polyion multivalency can improve functionality of membraneless compartments. Nat. Commun. 115949

Cakmak FP, Marianelli AM, and Keating CD 2021 Phospholipid membrane formation templated by coacervate droplets. BioRxiv 2021.02.17.431720

Campbell TD, Febrian R, McCarthy JT, Kleinschmidt HE, Forsythe JG and Bracher PJ 2019 Prebiotic condensation through wet-dry cycling regulated by deliquescence. Nat. Commun. 104508

Carvalho JRG, et al. 2020 Biocompatibility and biodegradation of poly(lactic acid) (PLA) and an immiscible PLA/ poly( $\varepsilon$-caprolactone) (PCL) blend compatibilized by poly( $\varepsilon$-caprolactone-b-tetrahydrofuran) implanted in horses. Polym. J. 52 629-643

Chandru K, Guttenberg N, Giri C, Hongo Y, Butch C, Mamajanov I and Cleaves HJ 2018 Simple prebiotic synthesis of high diversity dynamic combinatorial polyester libraries. Commun. Chem. 130

Chandru K, Jia TZ, Mamajanov I, Bapat N and Cleaves HJ 2020a Prebiotic oligomerization and self-assembly of structurally diverse xenobiological monomers. Sci. Rep. 1017560

Chandru K, Mamajanov I, Cleaves HJ and Jia TZ 2020b Polyesters as a model system for building primitive biologies from non-biological prebiotic chemistry. Life $\mathbf{1 0}$ 6

Chao Y and Shum HC 2020 Emerging aqueous two-phase systems: from fundamentals of interfaces to biomedical applications. Chem. Soc. Rev. 49 114-142

Chen L, Remondetto GE and Subirade M 2006 Food protein-based materials as nutraceutical delivery systems. Trends Food Sci. Technol. 17 272-283

Chen IA and Walde P 2010 From self-assembled vesicles to protocells. Cold Spring Harb. Perspect. Biol. 2 a002170

Chen Y, Yuan M, Zhang Y, Liu S, Yang X, Wang K and Liu J 2020 Construction of coacervate-in-coacervate multicompartment protocells for spatial organization of enzymatic reactions. Chem. Sci. 11 8617-8625

Cho E and Lu Y 2020 Compartmentalizing cell-free systems: toward creating life-like artificial cells and beyond. ACS Synth. Biol. 9 2881-2901

Claassen S, du Toit E, Kaba M, Moodley C, Zar HJ and Nicol MP 2013 A comparison of the efficiency of five different commercial DNA extraction kits for extraction of DNA from faecal samples. J. Microbiol. Methods 94 $103-110$

Cleaves HJ 2012 Prebiotic chemistry: what we know, what we don't. Evolution 5 342-360

Cleaves HJ 2013 Prebiotic chemistry: geochemical context and reaction screening. Life 3 331-345
Cleaves HJ, Michalkova Scott A, Hill FC, Leszczynski J, Sahai N and Hazen R 2012 Mineral-organic interfacial processes: potential roles in the origins of life. Chem. Soc. Rev. 41 5502-5525

Crowe CD and Keating CD 2018 Liquid-liquid phase separation in artificial cells. Interface Focus 820180032

Dammes N and Peer D 2020 Paving the road for RNA therapeutics. Trends Pharmacol. Sci. 41 755-775

da Silva D, Kaduri M, Poley M, Adir O, Krinsky N, Shainsky-Roitman J and Schroeder A 2018 Biocompatibility, biodegradation and excretion of polylactic acid (PLA) in medical implants and theranostic systems. Chem. Eng. J. 340 9-14

Das S, Lengweiler UD, Seebach D and Reusch RN 1997 Proof for a nonproteinaceous calcium-selective channel in Escherichia coli by total synthesis from (R)-3-hydroxybutanoic acid and inorganic polyphosphate. Proc. Natl. Acad. Sci. USA 94 9075-9079

Dass AV, Jaber M, Brack A, Foucher F, Kee TP, Georgelin T and Westall F 2018 Potential role of inorganic confined environments in prebiotic phosphorylation. Life 87

Davis BW, Aumiller WM Jr, Hashemian N, An S, Armaou A and Keating CD 2015 Colocalization and sequential enzyme activity in aqueous biphasic systems: experiments and modeling. Biophys. J. 109 2182-2194

Deamer D 2017 The role of lipid membranes in life's origin. Life 75

Del Bianco C and Mansy SS 2012 Nonreplicating protocells. Acc. Chem. Res. 45 2125-2130

de Lemos LR, Santos IJB, Rodrigues GD, da Silva LHM and da Silva MCH 2012 Copper recovery from ore by liquid-liquid extraction using aqueous two-phase system. J. Hazard. Mater. 237-238 209-214

Deng N-N 2020 Complex coacervates as artificial membraneless organelles and protocells. Biomicrofluidics $\mathbf{1 4}$ 051301

Deng N-N and Huck WTS 2017 Microfluidic formation of monodisperse coacervate organelles in liposomes. Angew. Chem. Int. Ed Engl. 56 9736-9740

Deshpande S, et al. 2019 Spatiotemporal control of coacervate formation within liposomes. Nat. Commun. 10 1800

Detassis S, Grasso M, Del Vescovo V and Denti MA 2017 microRNAs make the call in cancer personalized medicine. Front Cell Dev Biol 586

Diamond AD and Hsu JT 1989 Fundamental studies of biomolecule partitioning in aqueous two-phase systems. Biotechnol. Bioeng. 34 1000-1014

Díaz-Reinoso B, Moure A, Domínguez H and Parajó JC 2006 Supercritical CO2 extraction and purification of compounds with antioxidant activity. J. Agric. Food Chem. 54 2441-2469

Ding Y, Wu F and Tan C 2014 Synthetic biology: a bridge between artificial and natural cells. Life 4 10921116 
Drino A and Schaefer MR 2018 RNAs, phase separation, and membrane-less organelles: are post-transcriptional modifications modulating organelle dynamics? Bioessays 40 e 1800085

Drobot B, Iglesias-Artola JM, Le Vay K, Mayr V, Kar M, Kreysing M, Mutschler H and Tang T-YD 2018 Compartmentalised RNA catalysis in membrane-free coacervate protocells. Nat. Commun. 93643

Dutta LP and Das M 2015 Coacervation - a method for drug delivery; in: Advancements of Medical Electronics (eds) S Gupta, S Bag, K Ganguly, I Sarkar, and P Biswas (New Delhi, IN: Springer) pp 379-386

Eghbal N and Choudhary R 2018 Complex coacervation: encapsulation and controlled release of active agents in food systems. Lebenson. Wiss. Technol. 90 254-264

Eixler S, Selig U and Karsten U 2005 Extraction and detection methods for polyphosphate storage in autotrophic planktonic organisms. Hydrobiologia $\mathbf{5 3 3}$ $135-143$

Endo M and Sugiyama H 2018 DNA origami nanomachines. Molecules 231766

Fagone P and Jackowski S 2009 Membrane phospholipid synthesis and endoplasmic reticulum function. J. Lipid Res. $50 \mathrm{~S} 311-\mathrm{S} 316$

Fares HM, Marras AE, Ting JM, Tirrell MV and Keating CD 2020 Impact of wet-dry cycling on the phase behavior and compartmentalization properties of complex coacervates. Nat. Commun. 115423

Feng C, et al. 2014 Immobilization of coacervate microcapsules in multilayer sodium alginate beads for efficient oral anticancer drug delivery. Biomacromolecules 15 985-996

Feng L, et al. 2020 An adenovirus-vectored COVID-19 vaccine confers protection from SARS-COV-2 challenge in rhesus macaques. Nat. Commun. 114207

Flory PJ 1942 Thermodynamics of High Polymer Solutions. J. Chem. Phys. 10 51-61

Flory PJ 1945 Thermodynamics of dilute solutions of high polymers. J. Chem. Phys. 13 453-465

Forni G and Mantovani A 2021 COVID-19 vaccines: where we stand and challenges ahead. Cell Death Differ. 28 626-639

Forsythe JG, Yu S-S, Mamajanov I, Grover MA, Krishnamurthy R, Fernández FM and Hud NV 2015 Angew. Chem. Int. Ed Engl. 54 9871-9875

Fox SW 1964 Thermal polymerization of amino-acids and production of formed microparticles on lava. Nature $\mathbf{2 0 1}$ 336-337

Fox SW 1965 A theory of macromolecular and cellular origins. Nature $205328-340$

Fox SW 1976 The evolutionary significance of phaseseparated microsystems. Orig. Life Evol. Biosph. 7 49-68

Fox SW and Harada K 1958 Thermal copolymerization of amino acids to a product resembling protein. Science $\mathbf{1 2 8}$ 1214
Fox SW and Harada K 1960 The thermal copolymerization of amino acids common to protein. J. Am. Chem. Soc. 82 3745-3751

Fox SW, Harada K and Vegotsky A 1959 Thermal polymerization of amino acids and a theory of biochemical origins. Experientia 15 81-84

Fox SW and Krampitz G 1964 Catalytic decomposition of glucose in aqueous solution by thermal proteinoids. Nature 203 1362-1364

Fraccia TP and Jia TZ 2020 Liquid crystal coacervates composed of short double-stranded DNA and cationic peptides. ACS Nano 14 15071-15082

Frankel EA, Bevilacqua PC and Keating CD 2016 Polyamine/nucleotide coacervates provide strong compartmentalization of $\mathrm{Mg} 2+$, nucleotides, and RNA. Langmuir 32 2041-2049

Frenkel-Pinter M, Sargon AB, Glass JB, Hud NV and Williams LD 2021 Transition metals enhance prebiotic depsipeptide oligomerization reactions involving histidine. RSC Adv. 11 3534-3538

Frerix A, Müller M, Kula M-R and Hubbuch J 2005 Scalable recovery of plasmid DNA based on aqueous two-phase separation. Biotechnol. Appl. Biochem. 42 $57-66$

Frerix A, Schönewald M, Geilenkirchen P, Müller M, Kula M-R and Hubbuch J 2006 Exploitation of coil-globule pDNA transition induced by small changes in temperature, $\mathrm{pH}$ salt and PEG compositions for directed partitioning in aqueous two phase systems. Langmuir 22 4282-4290

Furubayashi T, Ueda K, Bansho Y, Motooka D, Nakamura S, Mizuuchi R and Ichihashi N 2020 Emergence and diversification of a host-parasite RNA ecosystem through Darwinian evolution. Elife 9 e56038

Furukawa Y, Sekine T, Oba M, Kakegawa T and Nakazawa H 2008 Biomolecule formation by oceanic impacts on early Earth. Nat. Geosci. 2 62-66

Gagliardi A, Giuliano E, Venkateswararao E, Fresta M, Bulotta S, Awasthi V and Cosco D 2021 Biodegradable polymeric nanoparticles for drug delivery to solid tumors. Front. Pharmacol. 12601626

Gànti T 2003 Chemoton theory: theory of living systems (Berlin: Springer)

Garenne D, Beven L, Navailles L, Nallet F, Dufourc EJ and Douliez J-P 2016 Sequestration of proteins by fatty acid coacervates for their encapsulation within vesicles. Angew. Chem. Int. Ed Engl. 55 13475-13479

Ghalia MA and Dahman Y 2017 Biodegradable poly(lactic acid)-based scaffolds: synthesis and biomedical applications. J. Polym. Res. 2474

Ghosh B, Bose R and Tang T-YD 2020 Can coacervation unify disparate hypotheses in the origin of cellular life? Curr. Opin. Colloid Interface Sci. 52101415 
Ghosh S, Mohajerani F, Son S, Velegol D, Butler PJ and Sen A 2019 Motility of enzyme-powered vesicles. Nano Lett. 19 6019-6026

Gillams RJ and Jia TZ 2018 Mineral surface-templated selfassembling systems: case studies from nanoscience and surface science towards origins of life research. Life $\mathbf{8} 10$

Gray MJ, et al. 2014 Polyphosphate is a primordial chaperone. Mol. Cell 53 689-699

Grote M 2011 Jeewanu, or the 'particles of life.' J. Biosci. 36 $563-570$

Gupta VK 2014 Emergence of photoautotrophic minimal protocell-like supramolecular assemblies, "Jeewanu" synthesied photo chemically in an irradiated sterilised aqueous mixture of some inorganic and organic substances. Orig. Life Evol. Biosph. 44 351-355

Gupta VK and Rai RK 2018 Cytochemical characterisation of photochemically formed, self-sustaining, abiogenic, protocell-like, supramolecular assemblies "Jeewanu." Int. J. Life Sci. 6 877-884

Gutierrez JMP, Hinkley T, Taylor JW, Yanev K and Cronin L 2014 Evolution of oil droplets in a chemorobotic platform. Nat. Commun. 55571

Guttenberg N, Virgo N, Chandru K, Scharf C and Mamajanov I 2017 Bulk measurements of messy chemistries are needed for a theory of the origins of life. Philos. Trans. A Math. Phys. Eng. Sci. 37520160347

Haldane JBS 1929 Origin of life. Ration. Annu. 148 3-10

Hamta A and Dehghani MR 2017 Application of polyethylene glycol based aqueous two-phase systems for extraction of heavy metals. J. Mol. Liq. 231 20-24

Hanczyc MM 2014 Droplets: unconventional protocell model with life-like dynamics and room to grow. Life 4 1038-1049

Hansma HG 2014 The power of crowding for the origins of life. Orig. Life Evol. Biosph. 44 307-311

Hargreaves WR and Deamer DW 1978 Liposomes from ionic, single-chain amphiphiles. Biochemistry 17 3759-3768

Helfrich MR, Mangeney-Slavin LK, Long MS, Djoko KY and Keating CD 2002 Aqueous phase separation in giant vesicles. J. Am. Chem. Soc. 124 13374-13375

Horton RH and Lucassen AM 2019 Recent developments in genetic/genomic medicine. Clin. Sci. 133 697708

Huang Y, Wang Y, Alexandre MR, Lee T, Rose-Petruck C, Fuller M and Pizzarello S 2005 Molecular and compound-specific isotopic characterization of monocarboxylic acids in carbonaceous meteorites. Geochim. Cosmochim. Acta 69 1073-1084

Huggins ML 1942 Theory of solutions of high polymers. $J$. Am. Chem. Soc. 64 1712-1719

Husmann M, Schenderlein S, Lück M, Lindner $\mathrm{H}$ and Kleinebudde P 2002 Polymer erosion in PLGA microparticles produced by phase separation method. Int. J. Pharm. 242 277-280
Hu B, Weng Y, Xia X-H, Liang X-J and Huang Y 2019 Clinical advances of siRNA therapeutics. J. Gene Med. 21 e3097

Hu B, Zhong L, Weng Y, Peng L, Huang Y, Zhao Y and Liang X-J 2020 Therapeutic siRNA: state of the art. Signal Transduct Target Ther. 5101

Ifeduba EA and Akoh CC 2015 Microencapsulation of stearidonic acid soybean oil in complex coacervates modified for enhanced stability. Food Hydrocoll. 51 136-145

Imai M and Walde P 2019 Giant unilamellar vesicles: From protocell models to the construction of minimal cells; in: The Giant Vesicle Book (Boca Raton, FL, USA: CRC Press) pp 569-583

Indulkar AS, Gao Y, Raina SA, Zhang GGZ and Taylor LS 2016 Exploiting the phenomenon of liquid-liquid phase separation for enhanced and sustained membrane transport of a poorly water-soluble drug. Mol. Pharm. 13 2059-69

Iqbal M, et al. 2016 Aqueous two-phase system (ATPS): an overview and advances in its applications. Biol. Proced. Online 1818

Ito Y, Uemura T and Nakano A 2014 Formation and maintenance of the Golgi apparatus in plant cells. Int. Rev. Cell Mol. Biol. 310 221-287

Jackson LA, et al. 2020 An mRNA vaccine against SARSCoV-2-preliminary report. N. Engl. J. Med. $\mathbf{3 8 3}$ 1920-1931

Jeong S, Nguyen HT, Kim CH, Ly MN and Shin K 2020 Toward artificial cells: novel advances in energy conversion and cellular motility. Adv. Funct. Mater. 301907182

Jia TZ, Bapat NV, Verma A, Mamajanov I, Cleaves HJ and Chandru K 2021 Incorporation of basic $\alpha$-hydroxy acid residues into primitive polyester microdroplets for RNA segregation. Biomacromolecules 22 1484-1493

Jia TZ, Caudan M and Mamajanov I 2021 Origin of species before origin of life: the role of speciation in chemical evolution. Life $\mathbf{1 1} 154$

Jia TZ, Chandru K, Hongo Y, Afrin R, Usui T, Myojo K and Cleaves HJ 2019 Membraneless polyester microdroplets as primordial compartments at the origins of life. Proc. Natl. Acad. Sci. USA 116 15830-15835

Jia TZ and Fraccia TP 2020 Liquid crystal peptide/DNA coacervates in the context of prebiotic molecular evolution. Crystals 10964

Jia TZ, Hentrich C and Szostak JW 2014 Rapid RNA exchange in aqueous two-phase system and coacervate droplets. Orig. Life Evol. Biosph. 44 1-12

Jiang S, Fagman JB, Chen C, Alberti S and Liu B 2020 Protein phase separation and its role in tumorigenesis. Elife 9 e60264

Jing H, Bai Q, Lin Y, Chang H, Yin D and Liang D 2020 Fission and internal fusion of protocell with membraneless "organelles" formed by liquid-liquid phase separation. Langmuir 36 8017-8026 
Jing H, Lin Y, Chang H, Bai Q and Liang D 2019 Dynamic behavior of complex coacervates with internal lipid vesicles under nonequilibrium conditions. Langmuir 35 $5587-5593$

Jiskoot W, van Schie RMF, Carstens MG and Schellekens H 2009 Immunological risk of injectable drug delivery system. Pharm. Res. 26 1303-1314

Jöbstl E, O'Connell J, Fairclough JPA and Williamson MP 2004 Molecular model for astringency produced by polyphenol/protein interactions. Biomacromolecules 5 942-949

Johnson NR and Wang Y 2014 Coacervate delivery systems for proteins and small molecule drugs. Exp. Opin. Drug Deliv. 11 1829-1832

Jordan SF, Rammu H, Zheludev IN, Hartley AM, Maréchal A and Lane N 2019 Promotion of protocell self-assembly from mixed amphiphiles at the origin of life. Nat. Ecol. Evol. 3 1705-1714

Juttulapa M, Piriyaprasarth S, Takeuchi H and Sriamornsak P 2017 Effect of high-pressure homogenization on stability of emulsions containing zein and pectin. Asian J. Pharm. Sci. 12 21-27

Kamimura YR and Kanai M 2021 Chemical insights into liquid-liquid phase separation in molecular biology. Bull. Chem. Soc. Jpn. 94 1045-1058

Kanagal-Shamanna R 2016 Emulsion PCR: techniques and applications. Methods Mol. Biol. 1392 33-42

Karthick V, et al. 2019 Quercetin loaded PLGA microspheres induce apoptosis in breast cancer cells. Appl. Surf. Sci. 487 211-217

Keating CD 2012 Aqueous phase separation as a possible route to compartmentalization of biological molecules. Acc. Chem. Res. 45 2114-2124

Keefe AD and Miller SL 1995 Are polyphosphates or phosphate esters prebiotic reagents? J. Mol. Evol. 41 693-702

Khan BM, Cheong K-L and Liu Y 2019 ATPS: "Aqueous two-phase System" as the "Answer to Protein Separation" for protein-processing Food Industry. Crit. Rev. Food Sci. Nutr. 59 3165-3178

Knab B 2016 Origins of Life Research Does Not Rest on a Mistake. Ergo 3 12405314.0003.026

Koga S, Williams DS, Perriman AW and Mann S 2011 Peptide-nucleotide microdroplets as a step towards a membrane-free protocell model. Nat. Chem. 3 720-724

Kojima T and Takayama S 2018 Membraneless compartmentalization facilitates enzymatic cascade reactions and reduces substrate inhibition. ACS Appl. Mater. Interfaces 10 32782-32791

Koonin EV 2012 Does the central dogma still stand? Biol. Direct 727

Kopinke F-D, Remmler M, Mackenzie K, Möder M and Wachsen O 1996 Thermal decomposition of biodegradable polyesters. II. Poly(lactic acid). Polym. Degrad. Stab. 53 329-342
Kreysing M, Keil L, Lanzmich S and Braun D 2015 Heat flux across an open pore enables the continuous replication and selection of oligonucleotides towards increasing length. Nat. Chem. 7 203-208

Krishnamurthy R 2018 Life's biological chemistry: a destiny or destination starting from prebiotic chemistry? Chemistry 24 16708-16715

$\mathrm{Ku}$ CA, Henry JD Jr and Blair JB 1989 Affinity-specific protein separations using ligand-coupled particles in aqueous two-phase systems: I. Process concept and enzyme binding studies for pyruvate kinase and alcohol dehydrogenase from Saccharomyces cerevisiae. Biotechnol. Bioeng. 33 1081-1088

Kvenvolden KA 1974 Amino and Fatty Acids in Carbonaceous Meteorites; in: The Origin of Life and Evolutionary Biochemistry (eds) K Dose, SW Fox, GA Deborin, and TE Pavlovskaya (New York, NY, USA: Springer) pp 301-309

Lagassé HAD, Alexaki A, Simhadri VL, Katagiri NH, Jankowski W, Sauna ZE and Kimchi-Sarfaty C 2017 Recent advances in (therapeutic protein) drug development. F1000Res 6113

Lai JC-Y, Pearce BKD, Pudritz RE and Lee D 2019 Meteoritic abundances of fatty acids and potential reaction pathways in planetesimals. Icarus 319 685-700

Lanham UN 1952 Oparin's hypothesis and the evolution of nucleoproteins. Am. Nat. 86 213-218

Last MGF, Deshpande S and Dekker C 2020 pH-Controlled coacervate-membrane interactions within liposomes. ACS Nano 14 4487-4498

Lavickova B, Laohakunakorn N and Maerkl SJ 2020 A partially self-regenerating synthetic cell. Nat. Commun. 116340

Lazcano A 2010 Historical development of origins research. Cold Spring Harb. Perspect. Biol. 2 a002089

Lazcano A and Miller SL 1996 The origin and early evolution of life: prebiotic chemistry, the pre-RNA world, and time. Cell 85 793-798

Lee YS, Lim K and Minteer SD 2021 Advances in electrochemical cofactor regeneration: enzymatic and non-enzymatic approaches. Annu. Rev. Phys. Chem. 72 467-488

Licatalosi DD, et al. 2008 HITS-CLIP yields genome-wide insights into brain alternative RNA processing. Nature $456464-469$

Li Y, Lipowsky R and Dimova R 2008 Transition from complete to partial wetting within membrane compartments. J. Am. Chem. Soc. 130 12252-12253

Lindner SN, Vidaurre D, Willbold S, Schoberth SM and Wendisch VF 2007 NCgl2620 encodes a class II polyphosphate kinase in Corynebacterium glutamicum. Appl. Environ. Microbiol. 73 5026-5033

Lin Y, Jing H, Liu Z, Chen J and Liang D 2020 Dynamic behavior of complex coacervates with internal lipid 
vesicles under nonequilibrium conditions. Langmuir $\mathbf{3 6}$ 1709-1717

Lin Y, Mori E, Kato M, Xiang S, Wu L, Kwon I and McKnight SL 2016 Toxic PR poly-dipeptides encoded by the C9orf72 repeat expansion target LC domain polymers. Cell 167 789-802.e12

Liu Y, Lipowsky R and Dimova R 2019 Giant vesicles encapsulating aqueous two-phase systems: from phase diagrams to membrane shape transformations. Front Chem 7213

Long MS, Jones CD, Helfrich MR, Mangeney-Slavin LK and Keating CD 2005 Dynamic microcompartmentation in synthetic cells. Proc. Natl. Acad. Sci. USA 102 $5920-5925$

Lopes LM, de Moraes MA and Beppu MM 2020 Phase diagram and estimation of Flory-Huggins parameter of interaction of silk fibroin/sodium alginate blends. Front. Bioeng. Biotechnol. 8973

Love C, Steinkühler J, Gonzales DT, Yandrapalli N, Robinson T, Dimova R and Tang T-YD 2020 Reversible $\mathrm{pH}$-responsive coacervate formation in lipid vesicles activates dormant enzymatic reactions. Angew. Chem. Int. Ed. Engl. 59 5950-5957

Lu Y 2017 Cell-free synthetic biology: engineering in an open world. Synth. Syst. Biotechnol. 2 23-27

Lucien FP, Liong KK, Cotton NJ, Macnaughton SJ and Foster NR 1993 Separation of biomolecules using supercritical fluid extraction. Australas. Biotechnol. 3 $143-147$

Luisi PL, Walde P and Oberholzer T 1999 Lipid vesicles as possible intermediates in the origin of life. Curr. Opin. Colloid Interface Sci. 4 33-39

Luque N, Rubio S and Pérez-Bendito D 2007 Use of coacervates for the on-site extraction/preservation of polycyclic aromatic hydrocarbons and benzalkonium surfactants. Anal. Chim. Acta 584 181-188

Lu T and Spruijt E 2020 Multiphase complex coacervate droplets. J. Am. Chem. Soc. 142 2905-2914

Madene A, Jacquot M, Scher J and Desobry S 2006 Flavour encapsulation and controlled release-a review. Int. J. Food Sci. Technol. 41 1-21

Malachowski T and Hassel A 2020 Engineering nanoparticles to overcome immunological barriers for enhanced drug delivery. Eng. Regener. $135-50$

Mamajanov I, et al. 2014 Ester formation and hydrolysis during wet-dry cycles: generation of far-from-equilibrium polymers in a model prebiotic reaction. Macromolecules 47 1334-1343

Mamajanov I 2019 Wet-dry cycling delays the gelation of hyperbranched polyesters: implications to the origin of life. Life 956

Manjare SD and Dhingra K 2019 Supercritical fluids in separation and purification: a review. Mater. Sci. Energy Technol. 2 463-484
Mann S 2012 Systems of creation: the emergence of life from nonliving matter. Acc. Chem. Res. 45 2131-2141

Manolio TA, et al. 2020 Genomic medicine year in review: 2020. Am. J. Hum. Genet. 107 1007-1010

Marszal E, Suchova M, Konecny P and Scouten WH 1995 Study of cell-free protein synthesis in aqueous two-phase systems. J. Mol. Recognit. 8 151-156

Martin N 2019 Dynamic synthetic cells based on liquidliquid phase separation. Chembiochem 20 2553-2568

Ma Q, Song Y, Sun W, Cao J, Yuan H, Wang X, Sun Y and Shum HC 2020 Cell-inspired all-aqueous microfluidics: from intracellular liquid-liquid phase separation toward advanced biomaterials. Adv. Sci. 71903359

Mastiani M, Firoozi N, Petrozzi N, Seo S and Kim M 2019 Polymer-salt aqueous two-phase system (ATPS) microdroplets for cell encapsulation. Sci. Rep. 915561

Mast CB, Schink S, Gerland U and Braun D 2013 Escalation of polymerization in a thermal gradient. Proc. Natl. Acad. Sci. USA. 110 8030-8035

Martín NY, Valer L and Mansy SS 2019 Toward long-lasting artificial cells that better mimic natural living cells. Emerg Top Life Sci 3 597-607

Mayer C, Schreiber U and Dávila MJ 2015 Periodic vesicle formation in tectonic fault zones - an ideal scenario for molecular evolution. Orig. Life Evol. Biosph. 45 139-148

Mayer C, Schreiber U and Dávila MJ 2017 Selection of prebiotic molecules in amphiphilic environments. Life 73

Mazzola PG, Lopes AM, Hasmann FA, Jozala AF, Penna TCV, Magalhaes PO, Rangel-Yagui CO and Pessoa A Jr 2008 Liquid-liquid extraction of biomolecules: an overview and update of the main techniques. J. Chem. Technol. Biotechnol. 83 143-157

McCollom TM, Ritter G and Simoneit BR 1999 Lipid synthesis under hydrothermal conditions by FischerTropsch-type reactions. Orig. Life Evol. Biosph. 29 153-166

McQueen L and Lai D 2019 Ionic liquid aqueous two-phase systems from a pharmaceutical perspective. Front. Chem. 7135

McSwiggen DT, Mir M, Darzacq X and Tjian R 2019 Evaluating phase separation in live cells: diagnosis, caveats, and functional consequences. Genes Dev. 33 1619-1634

Meng F and Ellis T 2020 The second decade of synthetic biology: 2010-2020. Nat. Commun. 115174

Mi X, Blocher McTigue WC, Joshi PU, Bunker MK, Heldt CL and Perry SL 2020 Thermostabilization of viruses via complex coacervation. Biomater. Sci. 8 7082-7092

Mikos AG, Thorsen AJ, Czerwonka LA, Bao Y, Langer R, Winslow DN and Vacanti JP 1994 Preparation and characterization of poly(l-lactic acid) foams. Polymer $\mathbf{3 5}$ 1068-1077

Mizuuchi R and Ichihashi N 2018 Sustainable replication and coevolution of cooperative RNAs in an artificial celllike system. Nat. Ecol. Evol. 2 1654-1660 
Mizuuchi R and Ichihashi N 2020 Translation-coupled RNA replication and parasitic replicators in membrane-free compartments. Chem. Commun. 56 13453-13456

Mizuuchi R and Ichihashi N 2021 Primitive compartmentalization for the sustainable replication of genetic molecules. Life 11191

Mohamed F and Van der Walle CF 2008 Engineering biodegradable polyester particles with specific drug targeting and drug release properties. J. Pharm. Sci. 97 $71-87$

Monnard P-A and Walde P 2015 Current Ideas about prebiological compartmentalization. Life 5 1239-1263

Mountain GA and Keating CD 2020 Formation of multiphase complex coacervates and partitioning of biomolecules within them. Biomacromolecules 21 630-640

Mountain GA and Keating CD 2021 Practical considerations for generation of multi-compartment complex coacervates. Methods Enzymol. 646 115-142

Mukherjee S 2019 Isolation and purification of industrial enzymes: advances in enzyme technology; in: Advances in Enzyme Technology (eds) RS Singh, RR Singhania, A Pandey, and C Larroche (Amsterdam, NL: Elsevier) pp 41-70

Müller WEG, Schröder HC and Wang X 2019 Inorganic polyphosphates as storage for and generator of metabolic energy in the extracellular matrix. Chem. Rev. 119 12337-12374

Mulligan MJ, et al. 2020 Phase I/II study of COVID-19 RNA vaccine BNT162b1 in adults. Nature 586 589-593

Muschiolik G and Dickinson E 2017 Double emulsions relevant to food systems: preparation, stability, and applications. Compr. Rev. Food Sci. Food Saf. 16 532-555

Nair SR 2010 Personalized medicine: striding from genes to medicines. Perspect. Clin. Res. 1 146-150

Nakashima KK, Baaij JF and Spruijt E 2018 Reversible generation of coacervate droplets in an enzymatic network. Soft Matter 14 361-367

Narayanaswamy R, Levy M, Tsechansky M, Stovall GM, O'Connell JD, Mirrielees J, Ellington AD and Marcotte EM 2009 Widespread reorganization of metabolic enzymes into reversible assemblies upon nutrient starvation. Proc. Natl. Acad. Sci. USA 106 10147-10152

Nojima T and Iyoda T 2017 Water-rich fluid material containing orderly condensed proteins. Angew. Chem. Int. Ed. Engl. 56 1308-1312

Nojima T, Niwa T and Taguchi H 2019 Proteome analysis of phase-separated condensed proteins with ionic surfactants revealed versatile formation of artificial bio-molecular condensates. Biomacromolecules 20 539-545

Norton JE, Gonzalez Espinosa Y, Watson RL, Spyropoulos $\mathrm{F}$ and Norton IT 2015 Functional food microstructures for macronutrient release and delivery. Food Funct. 6 663-678
Nott TJ, Craggs TD and Baldwin AJ 2016 Membraneless organelles can melt nucleic acid duplexes and act as biomolecular filters. Nat. Chem. 8 569-575

Nozawa R-S, Yamamoto T, Takahashi M, Tachiwana H, Maruyama R, Hirota T and Saitoh N 2020 Nuclear microenvironment in cancer: control through liquid-liquid phase separation. Cancer Sci. 111 3155-3163

Obata T 2019 Metabolons in plant primary and secondary metabolism. Phytochem. Rev. 18 1483-1507

Ocak B 2012 Complex coacervation of collagen hydrolysate extracted from leather solid wastes and chitosan for controlled release of lavender oil. J. Environ. Manag. 100 $22-28$

Okihana H and Ponnamperuma C 1982 A protective function of the coacervates against UV light on the primitive Earth. Nature 299 347-349

Ong JY and Torres JZ 2020 Phase separation in cell division. Mol. Cell 80 9-20

Oparin AI 1965 The origin of life (New York: Dover Publications)

Oshima T 1968 The catalytic hydrolysis of phosphate ester bonds by thermal polymers of amino acid. Arch. Biochem. Biophys. 126 478-485

Overbeek JT and Voorn MJ 1957 Phase separation in polyelectrolyte solutions; theory of complex coacervation. J. Cell. Physiol. Suppl. 49 7-22; discussion, 22-26

Patel BH, Percivalle C, Ritson DJ, Duffy CD and Sutherland JD 2015 Common origins of RNA, protein and lipid precursors in a cyanosulfidic protometabolism. Nat. Chem. 7 301-307

Patil SD, Rhodes DG and Burgess DJ 2005 DNA-based therapeutics and DNA delivery systems: a comprehensive review. AAPS J. 7 E61-E77

Peng L, Li E-M and Xu L-Y 2020 From start to end: phase separation and transcriptional. Biochim. Biophys. Acta Gene Regul. Mech. 1863194641

Peretó J 2005 Controversies on the origin of life. Int. Microbiol. 8 23-31

Phillips ML 2010 The origins divide: reconciling views on how life began. BioScience 60 675-680

Piras V, Tomita M and Selvarajoo K 2012 Is central dogma a global property of cellular information flow? Front. Physiol. 3439

Pir Cakmak F, Grigas AT and Keating CD 2019 Lipid vesicle-coated complex coacervates. Langmuir 35 7830-7840

Pir Cakmak F and Keating CD 2017 Combining catalytic microparticles with droplets formed by phase coexistence: adsorption and activity of natural clays at the aqueous/ aqueous interface. Sci. Rep. 73215

Pols T, Sikkema HR, Gaastra BF, Frallicciardi J, Śmigiel WM, Singh S and Poolman B 2019 A synthetic metabolic network for physicochemical homeostasis. Nat. Commun. 104239 
Porto TS, et al. 2008 Liquid-liquid extraction of proteases from fermented broth by PEG/citrate aqueous two-phase system. Chem. Eng. Process. 47 716-721

Poudyal RR, Guth-Metzler RM, Veenis AJ, Frankel EA, Keating CD and Bevilacqua PC 2019a Template-directed RNA polymerization and enhanced ribozyme catalysis inside membraneless compartments formed by coacervates. Nat. Commun. 10490

Poudyal RR, Keating CD and Bevilacqua PC 2019b Polyanion-assisted ribozyme catalysis inside complex coacervates. ACS Chem. Biol. 14 1243-1248

Poudyal RR, Pir Cakmak F, Keating CD and Bevilacqua PC 2018 Physical principles and extant biology reveal roles for RNA-containing membraneless compartments in origins of life chemistry. Biochemistry 57 2509-2519

Qiao Y, Li M, Booth R and Mann S 2017 Predatory behaviour in synthetic protocell communities. Nat. Chem. 9 110-119

Quirk S 2013 Enhanced catalytic activity from proteinoid microspheres. J. Biomed. Mater. Res. A 101 1133-1143

Raghavarao KSMS, Ranganathan TV, Srinivas ND and Barhate RS 2003 Aqueous two phase extraction-an environmentally benign technique. Clean Technol. Environ. Policy 5 136-141

Raja S and Murty VR 2013 Optimization of aqueous twophase systems for the recovery of soluble proteins from tannery wastewater using response surface methodology. J. Eng. 2013 1-10

Reinkemeier CD, Girona GE and Lemke EA 2019 Designer membraneless organelles enable codon reassignment of selected mRNAs in eukaryotes. Science $\mathbf{3 6 3}$ eaaw2644

Rosa PAJ, Azevedo AM, Sommerfeld S, Mutter A, AiresBarros MR and Bäcker W 2009 Application of aqueous two-phase systems to antibody purification: a multi-stage approach. J. Biotechnol. 139 306-313

Rutz JK, Borges CD, Zambiazi RC, Crizel-Cardozo MM, Kuck LS and Noreña CPZ 2017 Microencapsulation of palm oil by complex coacervation for application in food systems. Food Chem. 220 59-66

Sarkar S, Dagar S, Verma A and Rajamani S 2020 Compositional heterogeneity confers selective advantage to model protocellular membranes during the origins of cellular life. Sci. Rep. 104483

Sarkar S, Das S, Dagar S, Joshi MP, Mungi CV, Sawant AA, Patki GM and Rajamani S 2020 Prebiological membranes and their role in the emergence of early cellular life. $J$. Membr. Biol. 253 589-608

Sato Y, Sakamoto T and Takinoue M 2020 Sequence-based engineering of dynamic functions of micrometer-sized DNA droplets. Sci. Adv. 6 eaba3471

Schakenraad JM and Dijkstra PJ 1991 Biocompatibility of poly (DL-lactic acid/glycine) copolymers. Clin. Mater. 7 253-269

Scharf C, et al. 2015 A strategy for origins of life research. Astrobiology 15 1031-1042
Schrum JP, Zhu TF and Szostak JW 2010 The origins of cellular life. Cold Spring Harb. Perspect. Biol. 2 a002212

Schütte H 1997 Protein Purification by aqueous two-phase systems; in: Protein structure analysis (Berlin, DE: Springer) pp 31-48

Shang L and Zhao Y 2021 Droplet-templated synthetic cells. Matter 4 95-115

Shao K, Ding W, Wang F, Li H, Ma D and Wang H 2011 Emulsion PCR: a high efficient way of PCR amplification of random DNA libraries in aptamer selection. PLoS One 6 e 24910

Shin K 2019 Artificial cells containing sustainable energy conversion engines. Emerg. Top. Life Sci. 3 573-578

Shin H, Park YH, Kim Y-G, Lee JY and Park J 2018 Aqueous two-phase system to isolate extracellular vesicles from urine for prostate cancer diagnosis. PLoS One 13 e 0194818

Shive MS and Anderson JM 1997 Biodegradation and biocompatibility of PLA and PLGA microspheres. Adv. Drug Deliv. Rev. 28 5-24

Shpigelman A, Cohen Y and Livney YD 2012 Thermallyinduced $\beta$-lactoglobulin-EGCG nanovehicles: loading, stability, sensory and digestive-release study. Food Hydrocoll. 29 57-67

Sikkema HR, Gaastra BF, Pols T and Poolman B 2019 Cell fueling and metabolic energy conservation in synthetic cells. Chembiochem 20 2581-2592

Silveira MM, Moreira GMSG and Mendonça M 2021 DNA vaccines against COVID-19: perspectives and challenges. Life Sci. 267118919

Simoneit BRT, Rushdi AI and Deamer DW 2007 Abiotic formation of acylglycerols under simulated hydrothermal conditions and self-assembly properties of such lipid products. Adv. Space Res. 40 1649-1656

Singh R, Singh M, Arora G, Kumar S, Tiwari P and Kidwai S 2013 Polyphosphate deficiency in Mycobacterium tuberculosis is associated with enhanced drug susceptibility and impaired growth in guinea pigs. J. Bacteriol. 195 2839-2851

Smith DJ, et al. 2018 Airborne bacteria in earth's lower stratosphere resemble taxa detected in the troposphere: results from a new NASA aircraft bioaerosol collector (ABC). Front. Microbiol. 91752

Smith AE, Bellware FT and Silver JJ 1967 Formation of nucleic acid coacervates by dehydration and rehydration. Nature 214 1038-1040

Sokolova E, et al. 2013 Enhanced transcription rates in membrane-free protocells formed by coacervation of cell lysate. Proc. Natl. Acad. Sci. USA 110 1169211697

Song Y, Michaels TCT, Ma Q, Liu Z, Yuan H, Takayama S, Knowles TPJ and Shum HC 2018 Budding-like division of all-aqueous emulsion droplets modulated by networks of protein nanofibrils. Nat. Commun. 92110 
Sorrenti A, Illa O and Ortuño RM 2013 Amphiphiles in aqueous solution: well beyond a soap bubble. Chem. Soc. Rev. 42 8200-8219

Sperl JM and Sieber V 2018 Reaction design for the compartmented combination of heterogeneous and enzyme catalysis. ACS Catal. 8 2385-2396

Steinkühler J, Knorr RL, Zhao Z, Bhatia T, Bartelt SM, Wegner S, Dimova R and Lipowsky R 2020 Controlled division of cell-sized vesicles by low densities of membrane-bound proteins. Nat. Commun. 11905

Sutradhar KB and Amin ML 2013 Nanoemulsions: increasing possibilities in drug delivery. Eur. J. Nanomed.

Suzuki M, Kamihira M, Shiraishi T, Takeuchi H and Kobayashi T 1995 Affinity partitioning of protein a using a magnetic aqueous two-phase system. J. Ferment. Bioeng. 80 78-84

Sweetlove LJ and Fernie AR 2018 The role of dynamic enzyme assemblies and substrate channelling in metabolic regulation. Nat. Commun. 92136

Tanaka H 2012 Viscoelastic phase separation in soft matter and foods. Faraday Discuss. 158 371-406

Tang T-YD, Che Hak CR, Thompson AJ, Kuimova MK, Williams DS, Perriman AW and Mann S 2014 Fatty acid membrane assembly on coacervate microdroplets as a step towards a hybrid protocell model. Nat. Chem. 6 527-533

Tang T-YD, van Swaay D, deMello A, Anderson JLR and Mann S 2015 In vitro gene expression within membranefree coacervate protocells. Chem. Commun. 51 11429-11432

Tan SM, Kirchner R, Jin J, Hofmann O, McReynolds L, Hide W and Lieberman J 2014 Sequencing of captive target transcripts identifies the network of regulated genes and functions of primate-specific miR-522. Cell Rep. 8 1225-1239

Thewes S, Soldati T, and Eichinger L 2019 Amoebae as Host Models to Study the Interaction with Pathogens (Lausanne, CH: Frontiers Media SA)

Tian Y, Booth J, Meehan E, Jones DS, Li S and Andrews GP 2013 Construction of drug-polymer thermodynamic phase diagrams using Flory-Huggins interaction theory: identifying the relevance of temperature and drug weight fraction to phase separation within solid dispersions. Mol. Pharm. 10 236-248

Tinafar A, Jaenes K and Pardee K 2019 Synthetic biology goes cell-free. BMC Biol. 1764

Tirard S 2017 J. B. S. Haldane and the origin of life. $J$. Genet. 96 735-739

Tolstoguzov VB 1987 Creation of Fibrous Structures by Spinneretless Spinning; in: Food Structure: Creation and Evaluation (eds) JR Mitchell and JMV Blanshard (Cambridge, UK: Woodhead Publishing Limited) pp 181-196

Tolstoguzov VB 1993 Thermoplastic extrusion-the mechanism of the formation of extrudate structure and properties. J. Am. Oil Chem. Soc. 70 417-424
Tolstoguzov V 2000 Phase behaviour of macromolecular components in biological and food systems. Nahrung

Tolstoguzov V 2006 Texturising by phase separation. Biotechnol. Adv. 24 626-628

Trevors JT and Pollack GH 2005 Hypothesis: the origin of life in a hydrogel environment. Prog. Biophys. Mol. Biol. 89 1-8

Ura T, Yamashita A, Mizuki N, Okuda K and Shimada M 2021 New vaccine production platforms used in developing SARS-CoV-2 vaccine candidates. Vaccine 39 197-201

Urbánek T, Jäger E, Jäger A and Hrubý M 2019 Selectively biodegradable polyesters: nature-inspired construction materials for future biomedical applications. Polymers 111061

Valley B, Jing B, Ferreira M and Zhu Y 2019 Rapid and efficient coacervate extraction of cationic industrial dyes from wastewater. ACS Appl. Mater. Interfaces 11 7472-7478

van Stevendaal MHME, Vasiukas L, Yewdall NA, Mason AF and van Hest JCM 2021 Engineering of biocompatible coacervate-based synthetic cells. ACS Appl. Mater. Interfaces 13 7879-7889

Veis A 2011 A review of the early development of the thermodynamics of the complex coacervation phase separation. Adv. Colloid Interface Sci. 167 2-11

Vita-Finzi C and Fortes AD 2013 Planetary Geology: An Introduction (Edinburgh, UK: Dunedin Academic Press)

Walsh CT and Moore BS 2019 Enzymatic cascade reactions in biosynthesis. Angew. Chem. Int. Ed Engl. 58 6846-6879

Wang F, Altschuh P, Ratke L, Zhang H, Selzer M and Nestler B 2019 Progress report on phase separation in polymer solutions. Adv. Mater. 31 e1806733

Wang A and Szostak JW 2019 Lipid constituents of model protocell membranes. Emerg Top Life Sci 3 537-542

Washington KE, Kularatne RN, Karmegam V, Biewer MC and Stefan MC 2017 Recent advances in aliphatic polyesters for drug delivery applications. Wiley Interdiscip. Rev. Nanomed. Nanobiotechnol. 9 e1446

Westall F, et al. 2018 A hydrothermal-sedimentary context for the origin of life. Astrobiology 18 259-293

White R 2007 Does origins of life research rest on a mistake? Nous 41 453-477

Wu B-C, Degner B and McClements DJ 2014 Soft matter strategies for controlling food texture: formation of hydrogel particles by biopolymer complex coacervation. J. Phys. Condens. Matter 26464104

Xiao W, Jakimowicz MD, Zampetakis I, Neely S, Scarpa F, Davis SA, Williams DS and Perriman AW 2020 Biopolymeric coacervate microvectors for the delivery of functional proteins to cells. Adv. Biosyst. 4 e2000101

Xu C, Hu S and Chen X 2016 Artificial cells: from basic science to applications. Mater. Today 19 516-532 
Xu Y, Mazzawi M, Chen K, Sun L and Dubin PL 2011 Protein purification by polyelectrolyte coacervation: influence of protein charge anisotropy on selectivity. Biomacromolecules 12 1512-1522

Yamagata Y, Watanabe H, Saitoh M and Namba T 1991 Volcanic production of polyphosphates and its relevance to prebiotic evolution. Nature 352 516-519

Yau YK, Ooi CW, Ng E-P, Lan JC-W, Ling TC and Show PL 2015 Current applications of different type of aqueous two-phase systems. Bioresour. Bioprocess. 249

Yeo Y, Bellas E, Firestone W, Langer R and Kohane DS 2005 Complex coacervates for thermally sensitive controlled release of flavor compounds. J. Agric. Food Chem. 53 7518-7525

Yewdall NA, Amy Yewdall N, André AAM, Lu T and Spruijt E 2020 Coacervates as models of membraneless organelles. Curr. Opin. Colloid Interface Sci. 52101416

Yin Y, Niu L, Zhu X, Zhao M, Zhang Z, Mann S and Liang D 2016 Non-equilibrium behaviour in coacervate-based protocells under electric-field-induced excitation. Nat. Commun. 710658

Yoshizawa T, et al. 2018 Nuclear import receptor inhibits phase separation of FUS through binding to multiple sites. Cell 173 693-705.e22

Yoshizawa T, Nozawa R-S, Jia TZ, Saio T and Mori E 2020 Biological phase separation: cell biology meets biophysics. Biophys. Rev. 12 519-539

Yu S-S, Krishnamurthy R, Fernández FM, Hud NV, Schork FJ and Grover MA 2016 Kinetics of prebiotic depsipeptide formation from the ester-amide exchange reaction. Phys. Chem. Chem. Phys. 18 28441-28450

Zakrzewski W, Dobrzyński M, Szymonowicz M and Rybak Z 2019 Stem cells: past, present, and future. Stem Cell Res. Ther. $\mathbf{1 0} 68$

Corresponding editor: Kundan SenguPta
Zembyla M, Murray BS and Sarkar A 2020 Water-in-oil emulsions stabilized by surfactants, biopolymers and/or particles: a review. Trends Food Sci. Technol. 104 4959

Zhang Y and Fernie AR 2021 Metabolons, enzyme-enzyme assemblies that mediate substrate channeling, and their roles in plant metabolism. Plant Commun. 2100081

Zhang Z, Liu Q, Sun Z, Phillips BK, Wang Z, Al-Hashimi M, Fang L and Olson MA 2019 Poly-lipoic ester-based coacervates for the efficient removal of organic pollutants from water and increased point-of-use versatility. Chem. Mater. 31 4405-4417

Zhao J, et al. 2010 Genome-wide identification of polycomb-associated RNAs by RIP-seq. Mol. Cell $\mathbf{4 0}$ 939-953

Zhao W, Fan Y, Wang H and Wang Y 2017 Coacervate of polyacrylamide and cationic gemini surfactant for the extraction of methyl orange from aqueous solution. Langmuir 33 6846-6856

Zhao M and Zacharia NS 2018 Protein encapsulation via polyelectrolyte complex coacervation: protection against protein denaturation. $J$. Chem. Phys. $149 \quad 163$ 326

Zhu Q, Pan Y, Jia X, Li J, Zhang M and Yin L 2019 Review on the stability mechanism and application of water-in-oil emulsions encapsulating various additives. Compr. Rev. Food Sci. Food Saf. 18 1660-1675

Zolnik BS, González-Fernández A, Sadrieh N and Dobrovolskaia MA 2010 Nanoparticles and the immune system. Endocrinology 151 458-465

Zwicker D, Seyboldt R, Weber CA, Hyman AA and Jülicher F 2016 Growth and division of active droplets provides a model for protocells. Nat. Phys. 13 408-413 